\title{
ResearchGate
}

See discussions, stats, and author profiles for this publication at: https://www.researchgate.net/publication/233529544

\section{Reconciling Psychopathy and Low Self-Control}

ARTICLE in JUSTICE QUARTERLY · JUNE 2003

Impact Factor: $1.63 \cdot$ DOI: 10.1080/07418820300095541

CITATIONS

37

1 AUTHOR:

Richard Wiebe

Fitchburg State University

28 PUBLICATIONS 434 CITATIONS

SEE PROFILE
READS

60 


\title{
RECONCILING PSYCHOPATHY AND LOW SELF-CONTROL*
}

\author{
RICHARD P. WIEBE ${ }^{* * *}$ \\ Northeastern University
}

\begin{abstract}
Although both reflect a self-centered, antisocial personality, psychopathy and low self-control have seldom been examined together. This study created scales reflecting both common and unique elements of both constructs, investigated their factor structure, and explained variance in delinquency. Four alternative hypotheses were tested: that low self-control and psychopathy constitute a single construct, that they constitute primary and secondary psychopathy or interpersonal and intrapersonal traits, or that they constitute Antisociality - the tendency to perform antisocial acts - and (low) Self-Direction-the tendency to act in one's long-term beneft. Models containing Antisociality and Self-Direction fit better than alternatives and accounted for substantial variance in offending.
\end{abstract}

The construct of psychopathy that emerged from North American psychiatry in the 1940 s described persons who behaved in an unremittingly selfish manner, but seemed neither to regret their activities nor to learn from their failures (Cleckley, 1941; see also Gough, 1948). In this formulation, psychopathy was not thought to be strongly associated with crime. More recently, criminal psychologists have used the construct to distinguish among offenders and to predict offending and recidivism (e.g., Cunningham \& Reidy, 1998; Hare, 1980; Quinsey, 1995; see also Mealey, 1995). In this role, it falls squarely within traditions in psychiatry and psychology that

* This work was originally undertaken under the auspices of the 'Tucson Youth Project. I thank Janine Goldman-Pach for assistance with data collection, data management, and item selection; Donna Bishop, Bo Cleveland, and Alex Piquero, as well as several anonymous reviewers, for reading and critiquing carlier versions of this article; and Travis Hirschi for research collaboration and intellectual stimulation. Address correspondence to Richard P. Wiebe, College of Criminal Justice, Northeastern University, 400 Churchill Hall, Boston, MA 02115; e-mail: r.wiebe@neu,edu.

:** Richard P. Wiebe is an assistant professor at the College of Criminal Justice, Northeastern University. He earned a J.D. in 1983 from the University of Buffalo and a Ph.D in psychology in 1998 from the University of Arizona. Along with personality and crime, his current research interests include gene-environment interactions and other contextual effects on childhood and adolescent risk behavior.

JUSTICE QUARTERLY, Vol. 20 No. 2, June 2003

(C) 2003 Academy of Criminal Justice Sciences 
search for the roots of crime in the traits of criminals. This approach has been largely absent from mainstream sociological criminology, which tends to locate the causes of crime in the social forces that engulf ordinary people.

A notable exception within criminology is the "general theory of crime," promulgated by Gottfredson and Hirschi (1990). Central to this theory is the construct of low self-control, essentially an intrapersonal trait characterized by self-centeredness, impulsivity, and the inability or unwillingness to consider the long-term consequences of one's actions (Grasmick, Tittle, Bursik, \& Arneklev, 1993). Like Cleckley's (1941) conception of psychopathy, low selfcontrol is not thought to require crime, but simply to make it more likely to occur (Hirschi \& Gottfredson, 1993). Like psychopathy, low self-control has been invoked to explain behaviors that are not defined as criminal that nonetheless manifest a lack of concern for the rights or feelings of other people or for personal well-being (Cleckley, 1941; Hare, 1993; Hirschi \& Gottfredson, 1995; Widom, 1977). Unlike psychopathy, which is considered to be a mental disorder (Harpur, Hart, \& Hare, 1994), low self-control is thought to be the natural state of unsocialized individuals (Hirschi, 1994). Selfish acts, including crimes-"acts of force or fraud undertaken in pursuit of self-interest" (Gottfredson \& Hirschi, 1990, p. 15)-are their natural behaviors. Only the development of self-control or the elimination of opportunities for selfish behavior can prevent crime.

To predict offending, it may be inadvisable to rely solely on either low self-control or psychopathy. Although consistently found to have statistical significance, low self-control accounts for relatively little variance in offending: A recent meta-analysis found that low self-control generally explains between $5 \%$ and $9 \%$ of the variance in crime, delinquency, and other forms of deviance (Pratt \& Cullen, 2000). ${ }^{1}$ And as a predictor of crime, psychopathy is somewhat tautological: Four of the 20 items of the most commonly used instrument, the Psychopathy Checklist, Revised (PCL-R; Hare et al., 1990), measure some form of antisocial behavior itself (Lilienfeld, 1994; Raine, 1985), although the remaining elements correlate with crime (Hare \& Hart, 1993). Furthermore, psychopathy is thought to apply to only a particularly virulent subset of offenders, not offenders in general (Hare, 1996; Mealey, 1995). In sum, neither self-control, with its limited explanatory power (as currently measured), nor psychopathy, with its limited application to the population of offenders, is adequate by itself as a predictor of delinquency.

1 Although the addition of measures of criminal opportunity may improve the explained variance, it would not alter the conclusion that, as an intrapersonal predictor, low self-control accounts for less than $10 \%$ of the variance in offending. 
This article explores the relationship between psychopathy and low self-control, focusing on whether their separation in the research literature is justifiable, theoretically or empirically. Its goal is not to create new scales of either low self-control or psychopathy themselves, but rather to investigate their common and unique content to account better for the variance in delinquency. This investigation could then be continued by using scales derived from this study in conjunction with extant measures. But first, preliminary answers to the following questions would be useful: Should psychopathy and low self-control be considered discrete constructs or different manifestations of a single phenomenon? Or will other constructs emerge from their reconciliation that will be useful in explaining offending? The theoretical integration that follows begins to look at these questions.

\section{THEORETICAL INTEGRATION}

Although this integration seeks a common ground between psychopathy and self-control, this approach is not universally accepted. For example, in their presentation of self-control theory, Gottfredson and Hirschi (1990, p. 65, fn 1) rejected psychological theories of crime, including psychopathy, and many theorists of psychopathy have explicitly rejected any application of their construct to predict crime within the general population (Harris, Rice, \& Cormier, 1994). Nevertheless, each construct comprises several traits that collectively paint a coherent picture of a likely offender: a selfish, manipulative, careless individual with little ability to delay gratification, little interest in conventional pursuits, and little concern for the rights or feelings of others. Both psychopathy and self-control theorists would probably agree that not all offenders have all these traits in equal measure, but would further agree that each trait individually increases the probability of offending.

\section{Self-Control}

Self-control is considered by some to be the most important single characteristic that affects the quality of an individual's social relations. Gottfredson and Hirschi (1990) deemed low self-control "for all intents and purposes, the individual-level cause of crime" (p. 232) and, further, the cause of many noncriminal behaviors "analogous to crime," such as gambling, drinking, smoking, using drugs, engaging in "illicit sex," and having children out of wedlock. In its reach, it resembles self-control as described by some psychologists. For example, Baumeister and Exline (2000, p. 29) argued that "selfcontrol is central to most forms of virtuous behavior, and that it can 
be regarded fairly as the primary or master virtue"2 (cf. Wilson, 1993). This "master virtue" involves "control of the self by the self" (Muraven \& Baumeister, 2000, p. 247), with which an organism "alters or overrides its own responses or acts contrary to its preferences and impulses" (Baumeister \& Exline, 2000, p. 30). A similar construct has been called "behavioral self-control" and operationalized as the ability to delay gratification (Krueger, Caspi, Moffitt, White, \& Stouthamer-Loeber, 1996, p. 108; see also Wulfert, Block, Santa Ana, Rodriguez, \& Colsman, 2002).

At first glance, it appears that Gottfredson and Hirschi concurred. They concerned themselves mainly with low self-control, which they defined as the "tendency to pursue short-term, immediate pleasure" (1990, p. 93). In the extended statement of their theory, however, Gottfredson and Hirschi (1990) elaborated upon this parsimonious definition. As criminologists, their primary goal was to explain crime, unlike psychologists, whose field, they claimed, is "without any real disciplinary interest in the subject" (p. 69). Therefore, they began with a description of crime itself and inferred the intrapersonal characteristics of the offender from this description. In their view, criminal acts provide easy, simple, and immediate gratification of desires; require little skill or planning; are exciting, risky, or thrilling; provide few or meager long-term benefits; and often result in pain or discomfort for the victims. Thus, persons with low self-control lack diligence, tenacity, and persistence; find it difficult to delay gratification; have little tolerance for frustration and little ability to resolve problems through verbal, rather than physical, means; "need not possess or value cognitive or academic skills" or "manual skills that require training or apprenticeship" (p. 89); tend to be adventuresome, active, and physical; lack interest in, and preparation for, long-term pursuits, such as marriage and careers; and tend to be self-centered and indifferent or insensitive to the suffering and needs of others.

Gottfredson and Hirschi claimed that there is a "considerable tendency for these traits to come together in the same people" and "to persist through life." Therefore, "it seems reasonable to consider them as comprising a stable construct useful in the explanation of delinquent behavior" (1990, pp. 90-91). ${ }^{3}$ While some criminologists have used the narrower version (e.g., Polakowski, 1994; see also,

2 Others have granted it a smaller role. For example, Wilson (1993) considered it to be just one of several components of the "moral sense" that encourages individuals to behave prosocially in the absence of external sanctions, while Sampson and Laub (1993) considered it to be an important correlate of childhood misbehavior, but less predictive of the adult social bonds that directly affect offending:

3 Within criminology, considerable debate has ensued about whether self-control should be regarded as a unitary or a multifactorial construct. Studies have found a single factor (Arneklev, Grasmick, \& Bursik, 1999; Piquero \& Rosay, 1998; see also 
Rosay, 1999), and others have added sensation seeking to this version (LaGrange \& Silverman, 1999; Longshore et al., 1996), most have viewed "self-control" as the expanded set of traits listed by Gottfredson and Hirschi (see Pratt \& Cullen, 2000). ${ }^{4}$

\section{Psychopathy}

Unlike self-control, the construct of psychopathy was developed to account not for criminal behavior in general, but for antisocial behavior that was "inadequately motivated" (Cleckley, 1941). However, the most widely used modern measure, the PCL-R (Hare et al., 1990), explicitly includes antisocial behavior as part and parcel of psychopathy. In this view, psychopathy is a syndrome comprised of certain psychological characteristics and associated behaviors evincing self-centeredness, self-gratification, and an unconcern for others. According to some of its proponents, an individual PCL-R score indicates whether, not how much, psychopathy is present. In this view, psychopathy differs from low self-control in two ways: It is seen as a categorical, not a continuous, variable, and it comprises both antisocial behaviors and traits, rather than traits alone (e.g., Belmore \& Quinsey, 1994; but see Hare, 1996).

In contrast, some researchers have viewed psychopathy in a way that brings it closer to low self-control. They have proposed stripping psychopathy of antisocial behaviors and considering it solely as an intrapersonal syndrome--a collection of traits-that, like low self-control, predicts persistent criminal behavior and disrupted social relations (Lilienfeld, 1991, 1994; Raine, 1985). Furthermore, they have assumed that the traits comprising psychopathy can usefully be characterized as continuous (Blackburn, 1988; Harris, Rice, \& Quinsey, 1994; Levenson, Kiehl, \& Fitzpatrick, 1995; Lilienfeld, 1991; Lilienfeld \& Andrews, 1996).5

Polakowski, 1994) or five factors, with impulsivity and self-centeredness loading together (Longshore, Turner, \& Stein, 1996; see also Grasmick et al., 1993), though the five-factor solutions appear compatible with, or at least not clearly superior to, a single-factor solution (Arneklev et al., 1999; Longshore, Stein, \& Turner, 1998). Using item-response theory, Piquero, MacIntosh, and Hickman (2000) also questioned the unidimensionality of low self-control. However, each of these studies used a scale developed by Grasmick et al. (1993), which, as I argue in this article, may be an insufficient representation of low self-control.

4 According to Gottfredson and Hirschi (1990), other factors besides self-control help to determine whether crime will occur. One is the opportunity for crimes present in the environment: the easier they are to commit, the more of them will be committed. The others are intrapersonal characteristics that make crime more likely at any level of self-control: gregariousness and sociability and a high pain threshold or indifference to physical discomfort. Furthermore, certain traits can render a child difficult to socialize and hence at risk for low self-control: low intelligence, physical strength, a high activity level, and adventuresomeness.

5 There is some evidence that psychopathy's behavioral components may form a natural class, or taxon (Harris, Rice, \& Quinsey, 1994; see Meehl, 1992), but the evidence regarding its personality components is unclear. 
While researchers have generally agreed on the broad outline of psychopathy, they have not reached a consensus on its specific elements. The PCL-R is generally thought to consist of two separate but moderately correlated (at about $r=.5$ ) constructs (Harpur, Hare, \& Hakstian, 1989; Hare et al., 1990). The first factor represents a "selfish, callous, and remorseless use of others," and the second represents a "chronically unstable, antisocial, and socially deviant lifestyle" (Hare et al., 1990, p. 340; but see Lynam, Whiteside, \& Jones, 1999, pp. 127-128). The first factor loads on several mainly intrapersonal features from the PCL-R, including glibness and superficial charm, a grandiose sense of self-worth, pathological lying, manipulativeness, the lack of remorse or guilt, shallow affect, callousness and a lack of empathy, and failure to accept responsibility. The second factor loads on a mix of traits and behaviors, including the need for stimulation, a parasitic lifestyle, poor behavioral controls, early behavioral problems, the lack of realistic goals, impulsivity, irresponsibility, juvenile delinquency, and revocation of conditional release. Three additional features, each behavioral, fall outside both factors: promiscuity, many short-term relationships, and criminal versatility.

An alternate two-factor structure, one that does not include antisocial behaviors as part of psychopathy, was proposed by Levenson (1992) and Levenson et al. (1995). In this structure, such traits as selfishness and malevolence are considered "primary psychopathy," and traits like impulsiveness, heedlessness, and risk seeking are considered "secondary psychopathy." 6 In this formulation, secondary psychopathy resembles low self-control without the elements of self-centeredness. And the two-factor structure of

6 An alternative collection of psychopathic traits, based on factor analyses of individual items that produced a self-report scale that was free from antisocial behaviors, was compiled by Lilienfeld (1991; see also Lilienfeld \& Andrews, 1996). The scales of this Psychopathic Personality Inventory (PPI) include Machiavellian Egocentricity, Social Potency, Coldheartedness, Carefree Nonplanfulness, Fearlessness, Blame Externalization, Impulsive Nonconformity, and Stress Immunity (low anxiety). And another set of scales, derived from a pool of items from the Minnesota Multiphasic Personality Inventory and measures of hostility and aggression (Buss, 1961), as well as psychopathy (Peterson, Quay, \& Cameron, 1959), was compiled by Blackburn and Fawcett (1999). The scales of the Antisocial Personality Questionnarie (APQ) describe a more hostile, less blithe offender than do those of the PPI and include Self-Control, Self-Esteem, Paranoid Suspicion, (Social) Avoidance, Resentment, Aggression, Deviance (a measure of deviant social history), and Extraversion.

Other researchers have concentrated not on a multiplicity of traits, but on core features. For example, Levenson (1992, p. 66) considered primary psychopathy to be associated with "a set of assumptions which allow the world to be experienced exclusively in terms of personal gratification without anxiety concerning potential harm to others." These "assumptions," in turn, may facilitate the manipulative, egocentric, impulsive interpersonal style of many persistent offenders. Attitudes and beliefs that are similar to these assumptions have been proposed as important correlates of crime by criminologists (Hirschi, 1969; Sykes \& Matza, 1957) and psychologists (Bandura, 1977; see Maruna, 2001), although these researchers were not describing psychopaths. 
psychopathy was challenged by Cooke and Michie (2001), who proposed a tripartite scheme containing factors that represent intrapersonal characteristics, an "[a]rrogant and [d]eceitful [i]nterpersonal [s]tyle" (p. 176), and antisocial behaviors.

\section{Integrating Psychopathy and Low Self-Control}

As can be seen, many traits and behaviors associated with psychopathy are similar or identical to those associated with Gottfredson and Hirschi's (1990) version of low self-control. Each maps out a path to an antisocial life, in which immediate and selfish desires are gratified at the expense of both the rights and feelings of other people and one's own long-term interests. Gottfredson and Hirschi acknowledged the connection between low self-control and psychopathy when they quoted an article entitled "A Sociological Theory of Psychopathy" to illustrate their construct:

[D]rug use and delinquency are both manifestations of an underlying tendency to pursue short-term, immediate pleasure. This underlying tendency (i.e., lack of self-control) has many manifestations, as listed by Harrison Gough (1948, p. 362): "Unconcern over the rights and privileges of others when recognizing them would interfere with personal satisfaction in any way; impulsive behavior, or apparent incongruity between the strength of the stimulus and the magnitude of the behavioral response; inability to form deep or persistent attachments to other persons or to identify in interpersonal relationships; poor judgement and planning in attaining defined goals; apparent lack of anxiety and distress over social maladjustment and unwillingness or inability to consider maladjustment qua maladjustment; a tendency to project blame onto others and to take no responsibility for failures; meaningless prevarication, often about trivial matters in situations where detection is inevitable; almost complete lack of dependability ... and willingness to assume responsibility; and, finally, emotional poverty." (Gottfredson \& Hirschi, 1990, p. 93)

This portrait of psychopathy is roughly consistent with the intrapersonal elements of the PCL-R and illustrates the overlap between psychopathy and self-control. For a more thorough examination of the common and unique elements of each construct, see Table 1 .

As core features of psychopathy, other possibilities include a general disregard for personal safety (Lykken, 1957, 1995); the failure to introspect in critical life situations (Block \& Gjerde, 1986); social poise and a tendency to transfer or project blame (Reise \& Oliver, 1994); persistence in goal-directed behavior in the face of changing circumstances (Lynam, 1996); and the lack of social emotions, such as love and guilt, that facilitate reciprocal social interactions (Cleckley, 1941; Lykken, 1995; Mealey, 1995; see also Frank, 1988; Nesse, 1990; Wilson, 1993). 


\section{Table 1. Common and Unique Elements of Psychopathy and Low Self-control, and the Items Initially Chosen to Represent Them}

PCL-R (Hare \& Hart, 1993)

1. Glibness/superficial charm $(34,51,64)$

2. Grandiose sense of self-worth $(9,23$, $48,54)$

3. Need for stimulation/proneness to boredom $(17,18,43,44,45,53,56$, 58)

4. Pathological lying $(5,10,31,33,64)$

5. Conning/manipulative $(7,10,11,32$, $52,60,61,62$ )

6. Lack of remorse or guilt $(4,21,22$, $25,59,60)$

7. Shallow affect $(35,50)$

8. Callous/lack of empathy $(24,26,32)$

9. Parasitic life-style $(9,17,20)$

10. Poor behavioral controls $(1,2)$

11. Promiscuous sexual behavior $(36,37$, $38,39)$

13. Lack of realistic, long-term goals (19, 46, 47, 49)

14. Impulsivity $(28,30,55)$

15. Irresponsibility $(4,8,41,57)$

16. Failure to accept responsibility for actions $(3,6,12,40,60,63)$

None

None

None

Overt Behaviors That Are Not Part of the Item Pool

12. Early behavior problems

17. Many short-term marital relationships

18. Juvenile delinquency

19. Revocation of conditional release

20. Criminal versatility
Low Self-Control (Gottfredson \& Hirschi, 1990)

Self-centered

Self-centered

Risk taking/adventuresome, physical $^{\mathrm{a}}$

None

Self-centered

Self-centered, insensitive

None

Self-centered

Shortsighted, little interest in/ preparation for a career

Low frustration tolerance, nonverbal ${ }^{\text {b }}$

Illicit $\operatorname{sex}^{\mathrm{c}}$

Present orientation, little interest in/ preparation for a career, preference for simple tasks

Impulsivity, failure to delay gratification

Irresponsibility

Self-centered

Diligence/tenacity/persistence $(9,16$, 17, 20)

Gregariousness/sociability $(27,29$, $64)^{\mathrm{d}}$

Low commitment to family $(13,14$, $15)^{\mathrm{e}}$

Note: Item numbers (from Appendix A) are in parentheses. Several items were expected to cover more than one element.

a Physical orientation shows the lowest correlations with other elements of low selfcontrol (e.g. Arneklev et al., 1999) and is de-emphasized in subsequent formulations of self-control (Hirschi \& Gottfredson, 2001); therefore, it is de-emphasized here (see footnote 9).

${ }^{\mathrm{b}}$ Nonverbal aspects rot overtly addressed by frustration/lack of control items.

c According to Gottfredson and Hirschi, a correlate, not a component, of low selfcontrol.

d Not a component of self-control, but another predictor of crime, according to Gottfredson and Hirschi.

${ }^{\mathrm{e}}$ Element emphasized more strongly in social control theory (Hirschi, 1969). 
The derivation of "Self-Direction." Even if psychopathy and low self-control overlap, it is not clear how they relate to each other. One possibility is that, together, they constitute a single construct. Another possibility is that they constitute two constructs that parallel the two types of psychopathy described by Levenson et al. (1995): primary psychopathy, which includes traits related to selfcenteredness and manipulativeness, and secondary psychopathy, a narrower version of low self-control than that described by Gottfredson and Hirschi, which includes such traits as sensation seeking, impulsivity, and low diligence. A third possibility is that three factors will emerge that follow the distinction among traits, interpersonal styles, and behaviors derived from PCL-R data by Cooke and Michie (2001). But there is a fourth possibility, explored further in this article. Instead of concentrating solely on the correlates of antisocial behavior, which is thought to interfere with an individual's ability to achieve conventional success within society (Gottfredson \& Hirschi, 1990), researchers may profit from attending to intrapersonal correlates of behaviors that facilitate conventional success. These traits may include, most obviously, low levels of antisocial traits, but may also include traits that enable individuals to act in their own long-term best interests. Because the social, personal, and economic rewards of doing so will be greater than the ephemeral rewards of crime and deviance (Gottfredson \& Hirschi, 1990; Hirschi, 1969; Sampson \& Laub, 1993), pursuing conventional success through personal effort is expected to correlate negatively with offending. The overall construct containing the traits associated with this pursuit of conventional success can be called Self-Direction.

Although little specific attention has been paid to Self-Direction, it has not been completely ignored by criminologists (see, e.g., Glueck \& Glueck, 1950). Its seeds - the willingness to persist in future-oriented, goal-directed activities even in the absence of immediate external rewards, the ability to plan realistically for the future, and the belief that this persistence will ultimately benefit the individual-are present in research on both self-control and psychopathy. For example, psychopaths are thought to be unrealistic planners (Cleckley, 1964; Hare, 1993), and persons with low selfcontrol are thought to lack diligence and to be "little interested in and unprepared for long-term occupational pursuits" (Gottfredson \& Hirschi, 1990, p. 89). In contrast, a self-directed person is more likely to achieve conventional success, which can increase social capital and decrease the benefits of offending (Brannigan, 1997; Sampson \& Laub, 1993). 
Like self-control, Self-Direction can be found in research outside criminology. It resembles the psychological construct of selfefficacy-the belief that one's behavior will produce desired outcomes-but self-efficacy does not include the habit of diligence for its own sake (Bandura, 1986). One study found that an interaction between self-efficacy and prosocial values predicted deviant and risky behavior (Ludwig \& Pittman, 1999). Self-Direction also resembles conscientiousness from the Big Five and Five-Factor models of personality (Goldberg, 1990; McCrae \& John, 1992), which correlates negatively with delinquency (Heaven, 1996; Miller \& Lynam, 2001), as well as the construct of self-directedness from Cloninger, Svrakic, and Przybeck (1993), except that the latter construct does not include the element of persistence that Gottfredson and Hirschi (1990) included in their self-control construct and that is expected to constitute a central element of Self-Direction. ${ }^{7}$

\section{APPROACH OF THIS STUDY}

In this article, I present a study that sought to reconcile low self-control and psychopathy to improve the prediction of crime and delinquency from personality traits. If successful, this research would allow better understanding of the intrapersonal correlates of offending by combining the strengths of two heretofore discrete research traditions. As I noted earlier, the factor structures of both

7 The correspondence between Self-Direction and Conscientiousness elicited the question from one anonymous reviewer: Can the Big Five alone account for the psychological phenomena discussed in this article? Specifically, are Self-Direction and Antisociality variants of Conscientiousness and low Agreeableness, respectively? Miller, Lynam, Widiger, and Leukefeld (2001) examined this question with regard to psychopathy, using a panel of experts to generate a description of a prototypical psychopath in Big Five language. Although comparisons between this prototype and the Big Five scores of a sample of 481 young adults revealed significant correlations between a summary index, based on the prototype, calculated for each study participant, and all six facets (subscales) of the Agreeableness scale and two facets among men and four among women, of the Conscientiousness scale, significant correlations were also found for several facets of the Extroversion and Neuroticism scales. Furthermore, the Big Five-based index explained only $21 \%$ of the variance in a self-reported psychopathy measure. These findings suggest that there is much to psychopathy that does not overlap with the Big Five, at least not with the Agreeableness and Conscientiousness scales. An examination of the construct of selfcontrol reveals relatively more attention to the Conscientiousness scale.

One other issue is germane to the Big Five question. As originally developed, the Big Five comprised five broad dimensions of personality that were readily identifiable by ordinary people (Saucier \& Goldberg, 1996). Since the prototypical psychopath is not easily identifiable through dimensional scores alone, but has contradictory traits within these dimensions (low scores on the Anxiety subscale and high scores on the Angry Hostility subscale, for example, both within Neuroticism) (Miller et al., 2001), it seems clear that psychopaths are not readily identifiable by ordinary people (see also Hare, 1993) and will not show a simple Big Five profile, such as "low C, low A." That key persons cannot easily recognize psychpathy should not be surprising because psychopaths, with their primarily antisocial orientation (Mealey, 1995), as well as many other antisocial individuals, have ample incentive to hide their antisocial tendencies. The Antisociality dimension proposed here contains elements of self-justification, a cognitive device that has the effect of hiding one's antisocial nature from oneself and thus from others. 
psychopathy and self-control have been examined, and psychopathy, at least, appears factorially complex (Cooke \& Michie, 2001; Harpur et al., 1989; see fn 3). Because, together, the two constructs appear to contain a fuller set of traits associated with offending than either alone, I did not expect that previously generated factor structures will be duplicated. Instead, this study tested the assumption that both self-control and psychopathy researchers, by focusing more on offending than on nonoffending, have lost sight of the findings of Glueck and Glueck (1950) and others that psychological correlates of prosocial behavior may also help to explain antisocial behavior (see also Hirschi, 1969; Sampson \& Laub, 1993). Underlying this approach is the notion that to be completely socialized, a person must discover not only how to avoid crime, but what to do instead.

Thus, this study tested a model that contains two discrete constructs, one thought to facilitate antisocial behavior and the other, prosocial behavior. The first, Antisociality, represents the willingness to pursue one's immediate, selfish goals, despite the harm done to others. The second, Self-Direction, represents the willingness to work hard and prepare for the future even in the absence of immediate rewards, along with hope for the future. In contrast, low Self-Direction, expected to correlate positively with offending, represents the unwillingness to work hard and prepare for the future, despite the resultant harm to the self, combined with the belief that such work and preparation would be fruitless. Although related, I expected these dimensions to vary independently; for example, an individual who works hard and plays hard would be at a higher risk for offending than would someone who works hard and goes home to dinner with the family.

The study rests on the following foundation: (1) Psychopathy and low self-control are considered important correlates of crime, but by different academic disciplines; (2) their content overlaps considerably; (3) both comprise separate traits that may each independently correlate with delinquency; and (4) when combined in the same analysis, these traits will not necessarily form two constructs that conform to what is currently conceptualized as low self-control and psychopathy. By creating scales from a pool of items derived from both psychopathy and self-control research, I was able to test several hypotheses pertaining to the relationship between the two constructs and their ability, when combined appropriately, to predict delinquency.

I tested these hypotheses through factor analysis and structural equation modeling on data derived from a sample of university students. I assumed that traits, such as risk seeking and 
diligence, as well as higher-order constructs like psychopathy or Self-Direction, can be modeled as intrapersonal variables manifested by, in the case of traits, individual self-report items or, in the case of higher-order constructs, traits themselves. It is further possible that higher-order constructs can be combined at another level of organization, much as Factor 1 and Factor 2 of the PCL-R, comprised of various traits, are considered to be different facets of the overall construct of psychopathy (see Harpur et al., 1989; see also Raine, 1985).

\section{Hypotheses}

The first hypothesis is that each individual trait, created from the initial pool of items, will significantly predict delinquency. The second hypothesis pertains to the factor structure of the remaining traits. Using model-fitting procedures, I compared six alternatives: (1) a one-factor structure that assumes that psychopathy and selfcontrol are homologous and unidimensional (Model A); (2) a twofactor structure that reflects primary versus secondary psychopathy (Levenson et al., 1995), or malevolence versus carelessness (Model B); (3) a two-factor structure that reflects the model proposed in this article, Antisociality and Self-Direction (Model C); (4) a three-factor structure that reflects the model proposed by Cooke and Michie (2001), who distinguished among traits, interpersonal styles, and behaviors (Model D); (5) a model that uses the constructs from Model B to form a higher-order psychopathy/self-control construct (Model E); and (6) a model that uses the constructs from Model $\mathrm{C}$ to form the higher-order construct of self-control (Model F). I hypothesized that Models $\mathrm{C}$ and $\mathrm{F}$ will fit the data better than the other models. And the third hypothesis is that the bestfitting model will significantly predict delinquency and, more what is more important, will explain more variance than the $10 \%$ or less commonly reported for studies using only self-control (Pratt \& Cullen, 2000). ${ }^{8}$

\section{METHODS}

\section{Sample}

I used self-report data from a sample of 152 male and 155 female college students $(N=307)$, mainly (80\%) juniors or seniors, who completed surveys during classes at a southwestern university in 1996. Neither attendance nor survey completion was required. Of

8 This does not mean that the explanatory power of self-control theory faces a $10 \%$ ceiling, only that its intrapersonal variables seem limited in their explanatory power. When external variables (opportunity) are added, the explanatory power of the theory can increase. 
these students, $52 \%$ of their mothers and $62 \%$ of their fathers had earned a college degree or better. The income distribution was skewed upward: $5.4 \%$ reported a family income during high school of $\$ 20,000$ or less, with $17.1 \%$ reporting $\$ 20,000-\$ 39,000,22.8 \%$ reporting $\$ 40,000-\$ 59,000,17.4 \%$ reporting $\$ 60,000-\$ 79,000$, and $37.2 \%$ reporting $\$ 80,000$ or more. In addition $71 \%$ identified themselves as white, $16 \%$ identified themselves as Hispanic, $3 \%$ identified themselves as black, $8 \%$ identified themselves as Asian, and $2 \%$ identified themselves as Native American.

\section{Measures}

Psychopathy and self-control. An initial pool of 65 items came from several sources. Of the 65 items, 21 were drawn from the data used by Hirschi (1969) in his initial presentation of social control theory (the predecessor of self-control theory); 5 were drawn from the selfreport scale of self-control (the Grasmick scale), developed by Grasmick et al., 1993); and 2 were drawn from the work of Gibbs and Giever (1995). Other items were written for this study, and some were pilot-tested with college students. The items were scaled from $1=$ strongly agree to $5=$ strongly disagree (see Appendix A). ${ }^{9}$ These items were chosen to represent the elements of psychopathy and low self-control, as set forth in Table 1.

Crime and delinquency. According to self-control theory's stability hypothesis, current levels of self-control should reflect past levels of offending (Arneklev, Cochran, \& Gainey, 1998). Thus, the participants were asked whether they had ever taken part in seven activities-three categories of theft (less than $\$ 2, \$ 2-\$ 50$, over $\$ 50$ ), car theft or joyriding, vandalism, robbery, and assault (scored $1=$ never, $2=$ once or twice, $3=$ several times, or $4=$ many times). Three summary measures were constructed: (1) a combined frequency and versatility scale, using the original scoring; (2) a pure

9 One element from Gottfredson and Hirschi's $(1990$, p. 90) formulation of low self-control was not included in the initial pool of items, despite its previous inclusion in the Grasmick scale. The omitted element corresponds to the Grasmick subscale "preference for physical activities." This element has been de-emphasized in subsequent statements of the theory (Hirschi, 1994; Hirschi \& Gottfredson, 1995, 2001), perhaps because many manual skills requiring training or apprenticeship that can be acquired by persons with high self-control (Gottfredson \& Hirschi, 1990, p. 89) are "physical" in nature. Moreover, it has consistently exhibited the weakest correlations of all subscales with the overall Grasmick scale (Arneklev et al., 1999; Grasmick et al., 1993; Piquero \& Rosay, 1998).

The self-control items also diverged from the Grasmick scale in their representation of diligence. Though the Grasmick subscale entitled "preference for simple tasks" may represent a lack of diligence, it emphasizes the difficulty or complexity of the task, without acknowledging that many relatively simple tasks nonetheless require diligence to complete. 
versatility scale, created by combining the last three responses, resulting in each item scored as $1=$ never or $2=$ ever; and ( 3 ) a serious-offense scale, comprising only car theft, assault, robbery, and theft over $\$ 50$ (the four least-frequent behaviors), that used the binary scoring system. These scales were fairly reliable. The full 7 item scale had an alpha coefficient (Cronbach, 1951) of .82 when scored from 1 to 4 and .75 when scored 1 or 2 , while the seriousoffense scale had an alpha of .72 ( 1 to 4 ) and .64 ( 1 or 2 ). For comparison purposes, an alpha coefficient was computed for the lessserious offenses and was .73 ( 1 to 4 ) and .62 (1 or 2). An examination of these alphas reveals that adding the serious- and nonserious-offense scales together produces a more reliable scale than either does alone. Therefore, the decision was made to use the full 7-item scale for subsequent analyses.

Further indication that the offense items belonged on a single scale was provided by exploratory factor analyses (FAs). These analyses produced a single factor with an eigenvalue greater than 1, whether using a principal components, unweighted leastsquares, generalized least-squares, or maximum-likelihood procedure, although the chi-square statistic was significant. Moreover, a forced two-factor maximum-likelihood solution with oblique rotation produced substantial loadings (at least .345) for all items on both factors, leaving the two factors basically indistinguishable. The Kaiser-Meyer-Olkin (KMO) measure of sampling adequacy was .82, indicating that an FA of these variables was appropriate (Norusis, 1990).

Scales were created by taking the mean of each valid response. Using the mean, rather than summing responses, allows for withinsubjects estimates of missing data (Figueredo, Cox, \& Rhine, 1995). For the full 7-item scale scored 1 to 4 , the sample mean was 1.43, with a range of 1.0 to 4.0 , and was strongly skewed to the right with one long tail (skewness $=2.00, S E=.14$; kurtosis $=5.07, S E=.28$ ). For the 7-item scale with binary scoring, the sample mean was 1.32 , meaning that the average student reported about two different delinquent acts, with a range of 1.0 to 2.0 . This scale had a skewness of $.84(S E=.14)$ and a kurtosis of --.06 $(S E=.28)$. The binary serious-offense scale had a mean of 1.24 , a range of 1 to 4 , a skewness of $1.1(S E=.14)$, and a kurtosis of $.49(S E=.28)$. Transforming these scales with their natural logarithms reduced both skewness (1.08, $S E=.14)$ and kurtosis $(.99, S E=.28)$ for the 1 to 4 scale and skewness for the binary scale $(.48, S E=.14)$. The logarithmic binary scale was slightly bunched toward the middle of the distribution (kurtosis $=-.63, S E=.28$ ). Because its distribution was closest to normal and the 1 to 4 scoring system did not produce a linear scale, 
the logarithmic binary scale was used for the main models estimated in the study.

Although the sample comprised college students, offending levels were fairly high. For each item, the percentage of students who reported the behavior at least once were as follows: theft less than $\$ 2,64.1 \%$; theft between $\$ 2$ and $\$ 50,34.5 \%$; vandalism ("purposely destroyed or damaged public property"), 30.8\%; assault ("beaten up someone other than a brother or sister"), $27.4 \%$; robbery ("used force to get something from another person"), $27.2 \%$; car theft or joyriding ("driven a car without the owner's permission"), $21.3 \%$; and theft over $\$ 50,18.4 \%$. Overall, $78.4 \%$ of the sample reported at least one offense, and $51.0 \%$ reported at least one serious offense. In addition, $28.9 \%$ of the sample reported having been picked up by the police. Another illegal behavior, driving while intoxicated, was reported by $73.5 \%$ of the sample, but was omitted because it decreased reliability. At the other end of the scale, $21.6 \%$ of the sample- $32.3 \%$ of the female students and $10.6 \%$ of the male students-reported no delinquency whatsoever.

\section{Overview of the Analysis}

The analyses proceeded in several discrete steps. First, the pool of 65 items was subjected to an exploratory FA. Successive iterations resulted in a final pool of 51 items and 12 factors. Second, the factors were used to create a set of 12 scales. ${ }^{10}$ Third, the scales were individually correlated with delinquency (this and subsequent analyses were conducted separately by gender, as well as for the full sample). Those without significant correlations were omitted from subsequent analyses. Fourth, the remaining factors were combined into theoretically specified higher-order factors in confirmatory structural equation models (SEMs) to compare the three hypothesized models: a one-factor model corresponding to a unitary version of low self-control or psychopathy, a two-factor version corresponding to the two-factor structure of psychopathy, and a twofactor version that included the hypothesized constructs of Antisociality and Self-Direction. And fifth, the best-fitting measurement models were used to account for variance in self-reported delinquency.

10 The analytical methods used to construct the scales contrast with those of some previous studies (e.g. Blackburn \& Fawcett, 1999; Costello \& Vowell, 1999; Lilienfeld, 1991; Piquero \& Rosay, 1998) but comport with the methods of others (e.g., Quinsey, Book, \& Lalumiere, 2001). Because my aim was to create scales that are not sample specific, I used unit-weighted, rather than differentially weighted, factors (Figueredo et al., 1995). Because the underlying constructs are thought to be latent variables, I extracted factors, rather than principal components (Widaman, 1993). And because the constructs are thought to be correlated, I used oblique, rather than orthogonal, factor rotation (Basilevsky, 1994; Kim \& Mueller, 1978). 
The decision to begin with a pool of individual items, rather than full scales, such as the Grasmick scale of self-control or the PPI (Lilienfeld \& Andrews, 1996), stemmed from this study's goal of reconciling self-control and psychopathy. If the content of the two constructs truly overlaps, then some of their individual elements, as well as items measuring those elements, will overlap as well. Without allowing individual items from both constructs to form collective factors, it would be impossible to identify common content among individual elements because it would be impossible to discern which items were responsible for any significant correlations between elements of one construct and elements of the other.

\section{RESULTS}

Exploratory Factor Analysis

The analysis began with a series of exploratory FAs of the initial pool of 65 items, using the generalized least-squares method with an oblique (Promax) rotation ${ }^{11}$ among the 295 cases without missing data. Successive iterations winnowed items without loadings of at least .30 from the pool (Kim \& Mueller, 1978) and reduced the number of factors from the initial set of 16 with eigenvalues greater than 1 to a final model with 12 factors. This was the smallest number of factors that fit the data well $\left(\chi^{2}=786.2, d f=729, p=\right.$ $.070)$ and contained no uninterpretable or single-indicator factors. These steps produced a final pool of 51 items, for which the KMO was .761, indicating that an FA of these variables was probably appropriate (Norusis, 1990). The 12-factor model explained $46.2 \%$ of the variance among the items. In the final FA, all items except one, retained to increase coverage of empathy, loaded over 29 .

Interpretation of factors. With one exception, the factors seemed to correspond to self-control and psychopathy. Three factors seemed to represent elements of Factor 1 of the PCL-R-Manipulativeness, Antisocial Cognitions, and Guiltless--while two others-Anger and Risk seeking-appeared to fall within Factor 2. Each of these factors is consistent with the picture of an individual with low selfcontrol painted by Gottfredson and Hirschi (1990). The Manipulativeness factor seemed to constitute a truncated summary of three PCL-R elements-callous/lack of empathy, pathological liar, and conning/manipulative-none of which emerged as a pure factor. As is illustrated in Tables 1 and 2, 10 of the items that were designed

11 These methods were chosen to facilitate scale construction: generalized least-squares because it strongly weights items with substantial shared variance and Promax because it emphasizes strong loadings and minimizes weak ones (Tabachnick \& Fidell, 1996). 
to measure these three elements split between the Manipulativeness, Antisocial Cognitions, and Guiltless factors, while the remaining 5 had no important loadings on any factor. The 6th factor, Impulsive Sociability, seemed to straddle the two PCL-R factors, containing elements of impulsivity from Factor 2 and glibness/superficial charm from Factor 1. Impulsive Sociability does not correspond to any of the elements of low self-control; however, Gottfredson and Hirschi (1990) stated that gregarious persons will be more at risk for offending when levels of self-control are controlled. From these items, impulsivity did not emerge as a pure factor. The 7th factor, Lack of Commitment, reflected a preference for short-term sexual relations. This element is part of the PCL-R, but does not fall within either factor and is thought to be a behavioral manifestation of low self-control (Gottfredson \& Hirschi, 1990). Each of the first seven factors is expected to correlate positively with delinquency.

The 8th and 9th factors appear to describe prosocial traits, emphasized more in Hirschi's (1969) social control theory than in its successor, self-control theory (see Brownfield \& Sorenson, 1993). These factors are Attachment and Respect and are expected to correlate negatively with delinquency. The 10 th factor, also a prosocial trait, is Diligence, an element of (high) self-control but not psychopathy. The 11th factor, Shortsightedness, is also an element of low self-control and appears to correspond to the PCL-R Factor 2 items, "irresponsibility" and "lack of realistic goals." The final factor, the only one not to fall within either construct, was Sullen, indicating a shy person who dislikes school, hates some people, and holds grudges. This factor does not accord with the picture of the psychopath as glib and superficially charming. Under social control theory, however, this trait would be expected to correlate positively with delinquency because it would impede the formation of social bonds (see Hirschi, 1969; Sampson \& Laub, 1993). It also corresponds to the Resentment and (social) Avoidance scales of the Antisocial Personality Questionnaire developed by Blackburn and Fawcett (1999). Table 2 lists the factors and the corresponding elements of psychopathy and low self-control.

\section{Scale Construction}

Instead of using factor scores, which include trivial variance from items with low loadings, I constructed factor-based scales for use in subsequent analyses. Certain items were reverse coded, so that all items theoretically correlated positively with delinquency. Instead of using differentially weighted factors, which are sample specific, I computed scales as unit-weighted factors (Figueredo et 
Table 2. Comparison of Derived. Factors with Components of Psychopathy and Low Self-Control

\begin{tabular}{|c|c|c|}
\hline Derived factor & $\begin{array}{l}\text { PCL-R Item } \\
\text { (PCL-R factor) }\end{array}$ & Low Self-Control Component \\
\hline 1. Angry & $\begin{array}{l}\text { Poor behavioral controls }{ }^{\mathrm{a}} \\
\text { (2) }\end{array}$ & Low frustration tolerance \\
\hline \multirow[t]{2}{*}{$\begin{array}{l}\text { 2. Antisocial cogni- } \\
\text { tions }\end{array}$} & $\begin{array}{l}\text { Failure to accept respon- } \\
\text { sibility (1) }\end{array}$ & Self-centered \\
\hline & $\begin{array}{l}\text { Lack of remorse or guilt } \\
\text { (1) }\end{array}$ & \\
\hline 3. Attachment (r) & Irresponsibility (2) & $\begin{array}{l}\text { Irresponsibility, low commit- } \\
\text { ment to family }\end{array}$ \\
\hline 4. Diligent (r) & $\begin{array}{l}\text { Lack of realistic goals } \\
\text { (2) }\end{array}$ & $\begin{array}{l}\text { Lack of diligence, tenacity, per- } \\
\text { sistence; preference for sim- } \\
\text { ple tasks; little interest in/ } \\
\text { preparation for a career }\end{array}$ \\
\hline \multirow[t]{2}{*}{ 5. Guiltless } & $\begin{array}{l}\text { Lack of remorse or guilt } \\
\text { (1) }\end{array}$ & Self-centered \\
\hline & $\begin{array}{l}\text { Grandiose sense of self- } \\
\text { worth (1) }\end{array}$ & \\
\hline \multirow[t]{2}{*}{$\begin{array}{l}\text { 6. Impulsive socia- } \\
\text { bility }\end{array}$} & Impulsivity (2) & $\begin{array}{l}\text { Impulsivity; failure to delay } \\
\text { gratification }\end{array}$ \\
\hline & Glibness (1) & Sociability $^{\mathrm{c}}$ \\
\hline \multirow[t]{2}{*}{ 7. Low commitment } & $\begin{array}{l}\text { Short-term relationships } \\
\text { (neither) }\end{array}$ & Illicit sex ${ }^{a}$ \\
\hline & $\begin{array}{l}\text { Promiscuous sexual be- } \\
\text { havior (neither) }\end{array}$ & \\
\hline \multirow[t]{3}{*}{ 8. Manipulativeness } & $\begin{array}{l}\text { Conning/manipulative } \\
\text { (1) }\end{array}$ & Self-centered, insensitive \\
\hline & Pathological lying (1) & \\
\hline & $\begin{array}{l}\text { Callous/lack of empathy } \\
\text { (1) }\end{array}$ & \\
\hline 9. Respect (r) & Irresponsibility (2) & Irresponsibility \\
\hline 10. Risk seeking & Need for stimulation (2) & Risk taking/adventuresome \\
\hline \multirow[t]{4}{*}{ 11. Shortsighted } & Irresponsibility (2) & $\begin{array}{l}\text { Shortsighted, present orienta- } \\
\text { tion, little interest in/prepa- } \\
\text { ration for a career }\end{array}$ \\
\hline & Lack of realistic goals (2) & \\
\hline & Parasitic lifestyle (2) & \\
\hline & $\begin{array}{l}\text { Failure to accept respon- } \\
\text { sibility (1) }\end{array}$ & \\
\hline 12. Sullen & None $^{c}$ & None \\
\hline
\end{tabular}

Note: An (r) means that the factor theoretically correlates negatively with delinquency.

a The item "There are some people I hate," a component of both Angry and Sullen, seems to represent a more motivated antisocial person than a Cleckley (1941) psychopath.

b The PCL-R item represents only a portion of the derived factor.

${ }^{c}$ Not a component of self-control, but another predictor of crime, according to Gottfredson and Hirschi (1990).

d According to Gottfredson and Hirschi, a correlate, not a component, of low selfcontrol.

e Items on this factor contradict the PCL-R item grandiose sense of self-worth.

al., 1995). Each item was given a factor loading of 1.0, except for those shared between two different factors, which were given half the weight of unshared items. Scale scores were the arithmetic mean of nonmissing data. These procedures produced a full set of 
scales for 306 participants, 151 male and 155 female. To assess reliability, I calculated alpha coefficients. The scales and their reliability coefficients appear in Table 3.

Table 3. Constructs, Unit-Weighted Factor Scales, Reliabilities (Cronbach's alphas), Correlations with Offending (Pearson's $r$ )

\begin{tabular}{|c|c|c|c|c|c|c|c|c|}
\hline \multirow[b]{2}{*}{ Factor Scale } & \multicolumn{4}{|c|}{$\begin{array}{l}\text { Full sample } \\
(N=306)\end{array}$} & \multicolumn{2}{|c|}{$\begin{array}{l}\text { Women Only } \\
(N=155)\end{array}$} & \multicolumn{2}{|c|}{$\begin{array}{l}\text { Men Only } \\
(N=151)\end{array}$} \\
\hline & $\begin{array}{l}\text { No. of } \\
\text { Items }\end{array}$ & Alpha & $r$ & $p$ & $r$ & $p$ & $r$ & $p$ \\
\hline Anger & 2 & .74 & .17 & $.00 * *$ & .12 & .13 & .30 & $.00^{* * *}$ \\
\hline Antisocial Cognitions & 11 & .79 & .45 & $.00 * *$ & .35 & $.00 * *$ & .40 & $.00^{* *}$ \\
\hline Attachment & 3 & .81 & -.12 & $.04 *$ & -.11 & .16 & -.03 & .71 \\
\hline Diligence & 4 & .70 & -.30 & $.00 * *$ & -.20 & $.02^{*}$ & -.32 & $.00^{* * *}$ \\
\hline Guiltless & 6 & .50 & .15 & $.01^{* * *}$ & -.04 & .58 & .19 & $.02 *$ \\
\hline Impulsive Sociability & 5 & .62 & .25 & $.00 * *$ & .10 & .21 & .17 & $.04 *$ \\
\hline Low Commitment & 4 & .79 & .42 & $.00 * *$ & .21 & $.01^{* * *}$ & .20 & $.02 *$ \\
\hline Manipulativeness & 5 & .60 & .40 & $.00 * *$ & .36 & $.00 * *$ & .38 & $.00^{* *}$ \\
\hline Respect & 3 & .60 & -.11 & .07 & -.23 & $.00 * *$ & -.10 & .23 \\
\hline Risk Seeking & 4 & .60 & .27 & $.00 * *$ & .27 & $.00 * *$ & .11 & .20 \\
\hline Shortsightedness & 8 & .66 & .25 & $.00^{* * *}$ & .26 & $.00 * *$ & .22 & $.01 * *$ \\
\hline Sullen & 5 & .51 & .24 & $.00^{* *}$ & .23 & $.00^{* *}$ & .26 & $.00^{* *}$ \\
\hline
\end{tabular}

$* p \leq .05, * * p \leq .01$ (.00 means $\leq .005)$

\section{Bivariate Regressions}

The scales were then entered into bivariate regression analyses with self-reported delinquency. As Table 3 indicates, only the Respect scale failed to correlate significantly at the $p<.05$ level within the full sample. Four scales among females and three among males failed to achieve significance. Items and factor loadings appear in Appendix A. ${ }^{12}$ An analysis of correlations among its items revealed that the Guiltless scale was psychometrically problematic, so it was eliminated from subsequent statistical models.

\section{Confirmatory Analyses: SEMs}

Finally, SEMs, using the AMOS program (Arbuckle, 1999), were estimated to investigate the three alternative higher-order factor structures. ${ }^{13}$ Because no single test should be used for model

12 One item with two loadings over 30 , concerning saving money, was omitted from the Sullen scale because it decreased reliability and rendered the scale less intelligible. It was retained on the Diligence scale and was weighted as if it was shared with another factor.

13 One anonymous reviewer suggested that this procedure might violate the view, advocated by Hayduk and Glaser (2000), that using factor analysis prior to structural equation modeling amounts to illegitimate "peeking at the data" (p. 20). However, this principle appears to apply to nested models only. Because exploratory FA was used only to create scales and models containing the higher-order structure were theoretically prespecified, this objection would not seem to apply to the present 
evaluation (Bollen \& Long, 1993; Gerbing \& Anderson, 1993), several were used in the direct comparisons of the models and in the assessment of overall fit. The first, the Bayes information criterion (BIC), allows for the comparison of models to one another but does not indicate overall goodness of fit. Preferred models generate smaller BIC scores, but this criterion tends to favor parsimonious models more than the other criteria (Arbuckle \& Wothke, 1999).

The other fit indices permit the assessment of both relative and absolute fit. The most widely used is the overall model chi-square $\left(\chi^{2}\right)$, which should be nonsignificant in a good-fitting model (Arbuckle \& Wothke, 1999; but see Hayduk \& Glaser, 2000). Another, the root mean square error of approximation (RMSEA), should be under .05 for a good fit, between .05 and .08 for a reasonable fit, and between .08 and .10 for a mediocre fit; if it is above .10, it indicates an unacceptable fit (Diamantopoulos \& Siguaw, 2000). Two absolute fit indices, the goodness-of-fit index (GFI) and the adjusted GFI (AGFI), compare the estimated model to the actual sample covariance or correlation matrix. These indices range between 0 and 1.0 and should be at least .90 in a good-fitting model (Diamantopoulos \& Siguaw, 2000). Two practical fit indices, the normed fit index (NFI; Bentler \& Bonnett, 1980) and the comparative fit index (CFI; Bentler, 1990), compare the estimated model to an independence model. They also range between 0 and 1.0, and both should be at least .90 in a good-fitting model (Bentler, 1990). ${ }^{14}$ The multiplicity of indices is necessary because there is considerable disagreement in the SEM literature regarding the proper fit statistics to use (Diamantopoulos \& Siguaw, 2000; Hayduk, 1996). ${ }^{15}$

One final statistic is reported: a parsimony ratio (PRATIO). PRATIO simply compares the degrees of freedom in the tested model to those in the saturated model. A model with no paths would have a PRATIO of 1.0; thus, the more parsimonious the model, the higher the PRATIO.

All tested models were nested, meaning that they contained the same variables and differed only in structure, permitting direct comparisons among the models (Long, 1983). As paths were added and degrees of freedom lost, improvements in fit indices were corrected for parsimony in two ways. The first examined the statistical

research. Data from the exploratory $\mathrm{FA}$ were not used in any way to explore the higher-order factor structure of the scales, which is the main subject of this article.

14 The NFI and CFI constitute alternatives to $\chi^{2}$, which is sensitive to sample size (Bollen \& Long, 1993) and indicates only whether a model fits, not the degree of fit (Gerbing \& Anderson, 1993). The CFI is truncated at 1.000.

15 For example, Hayduk recommended the AGFI and the $\chi^{2}$, while Diamantopoulos and Siguaw recommended the GFI, RMSEA, CFI, and two others not previously mentioned, the standardized RMR and the ECVI. 
significance of the difference between the $\chi^{2}$ statistics for each model, with a significant difference favoring the less-parsimonious model (Long, 1983). The second used the conservative rule of thumb proposed by Widaman (1985), which accounts for the loss of degrees of freedom that often accompanies improvements in the NFI and CFI. Under this rule, each loss of one degree of freedom should be accompanied by a gain of at least .010 in the practical fit indices for the less-parsimonious model to be preferred. In contrast, values for the GFI, AGFI, BIC, and RMSEA were used to compare each model directly without adjusting for parsimony; the AGFI is the parsimony-adjusted GFI.

Measurement models. 'The first set of SEMs reflected Models A, B, and $\mathrm{C}$, as described earlier. Model A contained a single unitary low self-control and/or psychopathy factor, Model B contained two factors representing primary and secondary psychopathy, and Model C contained two factors representing Antisociality and Self-Direction. Model D was not estimated at this stage because it explicitly requires the inclusion of the Delinquency scale, used only for the structural models. These models used only a subset of the original scales. Because Respectful did not correlate significantly with delinquency among the full sample, it was not used in these analyses. Attachment was also not used because it described a particular relationship (with one's mother) and thus fit a social-control perspective better than the intrapersonal perspective of self-control and psychopathy research. Although Sullen correlated significantly with delinquency, it did not fit within any of the theoretical perspectives discussed here (and explained the least variance of all the factors in the initial extraction) and was also not used. Similarly, Impulsive Sociability appeared factorially complex and, insofar as it measures sociability, is not considered by self-control theory to constitute an element of low self-control. It too was omitted from subsequent models, leaving seven scales for confirmatory factor analysis.

These scales were arranged as follows. Model A modeled all seven scales as indicators of a single factor. Model B modeled Antisocial Cognitions and Manipulativeness as indicators of primary psychopathy and Anger, Risk Seeking, (low) Diligence, and Shortsightedness as indicators of secondary psychopathy. Because it is not part of either factor on the PCL-R, Low Commitment was allowed to load on either primary psychopathy, secondary psychopathy, or both. Model C modeled Antisocial Cognitions, Manipulativeness, Anger, Risk Seeking, and Low Commitment as indicators of Antisociality, and Diligence and Shortsightedness as indicators of Self-Direction. 
Of these models, both Models $\mathrm{A}$ and $\mathrm{B}$ fit only according to the GFI and the AGFI. In contrast, Model $\mathrm{C}$ achieved a good fit by the NFI and CFI, increased the GFI and AGFI substantially, generated a smaller BIC (139.3) than either model A (155.2) or B (160.6), and moved the RMSEA from the "mediocre" to the "reasonable" range (.053). To improve model fit, I tested theoretically derived correlations between error terms, based on items shared between scales (Byrne, 1994; Jöreskog, 1993; see Longshore et al., 1998). Each cost one degree of freedom, requiring model comparisons to be adjusted for parsimony.

With no error correlations, the two-factor model fit by all criteria except $\chi^{2}$. An error correlation between Shortsightedness and Risk Seeking improved the fit, but the parsimony criteria were ambiguous. Neither the GFI nor the AGFI improved substantially, and the BIC increased with each lost degree of freedom, from 139.3 through 143.6 to 148.6 . The NFI improved .011, favoring the new model, but the CFI improved only .008, and the difference in $\chi^{2}$ (3.472) was not significant. However, the model produced a nonsignificant $\chi^{2}$, indicating good fit, and the RMSEA improved from .053 to .049 , moving from the reasonable-fit into the good-fit category. Thus, this model fit by each criterion. A second error correlation, between Antisocial Cognitions and Shortsightedness, did not significantly improve the fit by the $\chi^{2}$, but resulted in an improvement in the NFI that nearly fulfilled Widaman's (1985) criterion when compared with the model with no error correlations (difference NFI $=.019, d f=2$ ), and decreased the RMSEA further, to .046 . Because of these ambiguities, all three versions of Model $\mathrm{C}$ were retained for further analysis, while both Model A and Model B were rejected. ${ }^{16}$ Fit indices for all models, and comparisons among them, appear in Table 4.

The next set of models attempted to fit a higher-order factor structure to the best-fitting models from the previous round. No higher-order versions of Model B achieved an acceptable fit, and higher-order versions of Model $\mathrm{C}$ fit identically to their two-factor foundations. The latter were therefore retained for further analyses because of their implications for predicting delinquency.

Structural models. In the next stage, the Delinquency scale was added, allowing the best-fitting measurement models to be used as the basis for structural models that examined both direct and indirect effects on delinquency of Antisociality and Self-Direction. Also at this stage, the model based on Cooke and Michie's (2000) model

16 The addition of error correlations to Models A and B failed to produce acceptable fit indices. 


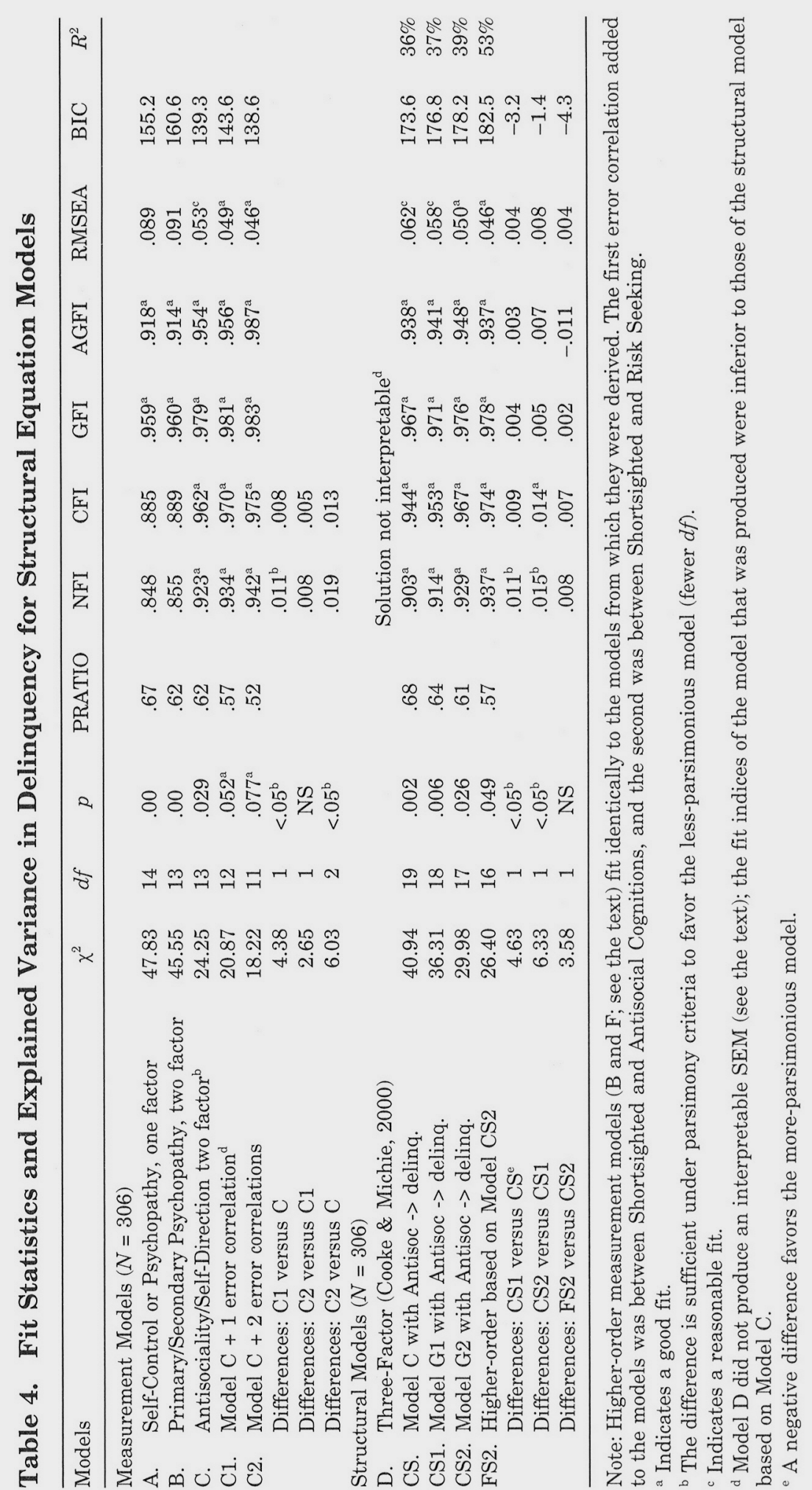


of psychopathy (Model D), which required the Delinquency factor, was estimated. This model placed Antisocial Cognitions, Risk Seeking, Anger, Shortsightedness, and Diligence on a factor representing intrapersonal characteristics, placed Low Commitment and Manipulativeness on a factor representing interpersonal styles, and used Delinquency to represent antisocial behaviors. This model produced mediocre fit indices $(\mathrm{NFI}=.870, \mathrm{CFI}=.901, \mathrm{RMSEA}=.089)$ and several standardized path coefficients greater than 1.0, rendering it uninterpretable (Long, 1983). This model was therefore rejected.

Structural models were then created from the best-fitting measurement models. The best-fitting structural model contained two error correlations, between Shortsighted and Antisocial Cognitions and between Shortsighted and Risk Seeking; a path from Antisociality to Delinquency; and no path from Self-Direction to Delinquency. This model fit well according to most of the fit indices, but produced a significant $\chi^{2}\left(\chi^{2}=29.983, d f=17, p=.026, \mathrm{GFI}=.976\right.$. $\mathrm{AGFI}=.948, \mathrm{NFI}=.929, \mathrm{CFI}=.967, \mathrm{RMSEA}=.050$ ). In this model, which accounted for $39 \%$ of the variance in offending, the effect of Self-Direction on delinquency was indirect. ${ }^{17}$ This model appears in Figure 1.

A higher-order model, with Antisociality and Self-Direction modeled as indicators of Self-Control and Self-Control the sole predictor of delinquency also fit the data well $\left(\chi^{2}=26.404, d f=16, p=\right.$ $.049, \mathrm{GFI}=.978, \mathrm{AGFI}=.951, \mathrm{NFI}=.937, \mathrm{CFI}=.974)$, increased both the GFI and the AGFI, and improved the RMSEA to .046, but the change in $\chi^{2}$ was not significant, the improvements in the practical fit indices were not sufficient to justify the loss of parsimony, and the BIC was higher than for the simpler model. This model accounted for $53 \%$ of the variance in offending.

Models were also run for males and females separately and produced similar results. The best models contained the Antisociality and the Self-Direction factors and had a single error correlation: between Shortsighted and Risk Seeking among females and between Shortsighted and Antisocial Cognitions among males. Like the full-sample model, both had a direct path from Antisociality to Delinquency, and neither had a direct path from Self-Direction to

17 As an anonymous reviewer noted, the model could have been illustrated by an arrow going from Self-Direction to Antisociality, which would have represented a mediation effect, but it also would have implied that Self-Direction somehow causes Antisociality. No such hypothesis is advanced here. Since both are latent variables representing intrapersonal traits that presumably developed long before the crosssectional data were collected for this study, the more conservative covariance model (the double-headed arrow) was retained. A model with an arrow from Self-Direction to Antisociality (and an error term for Antisociality, which would no longer be exogenous) fits identically in all respects to the model with the double-headed arrow. 
Figure 1. Best-Fitting Two-Factor Structural Model

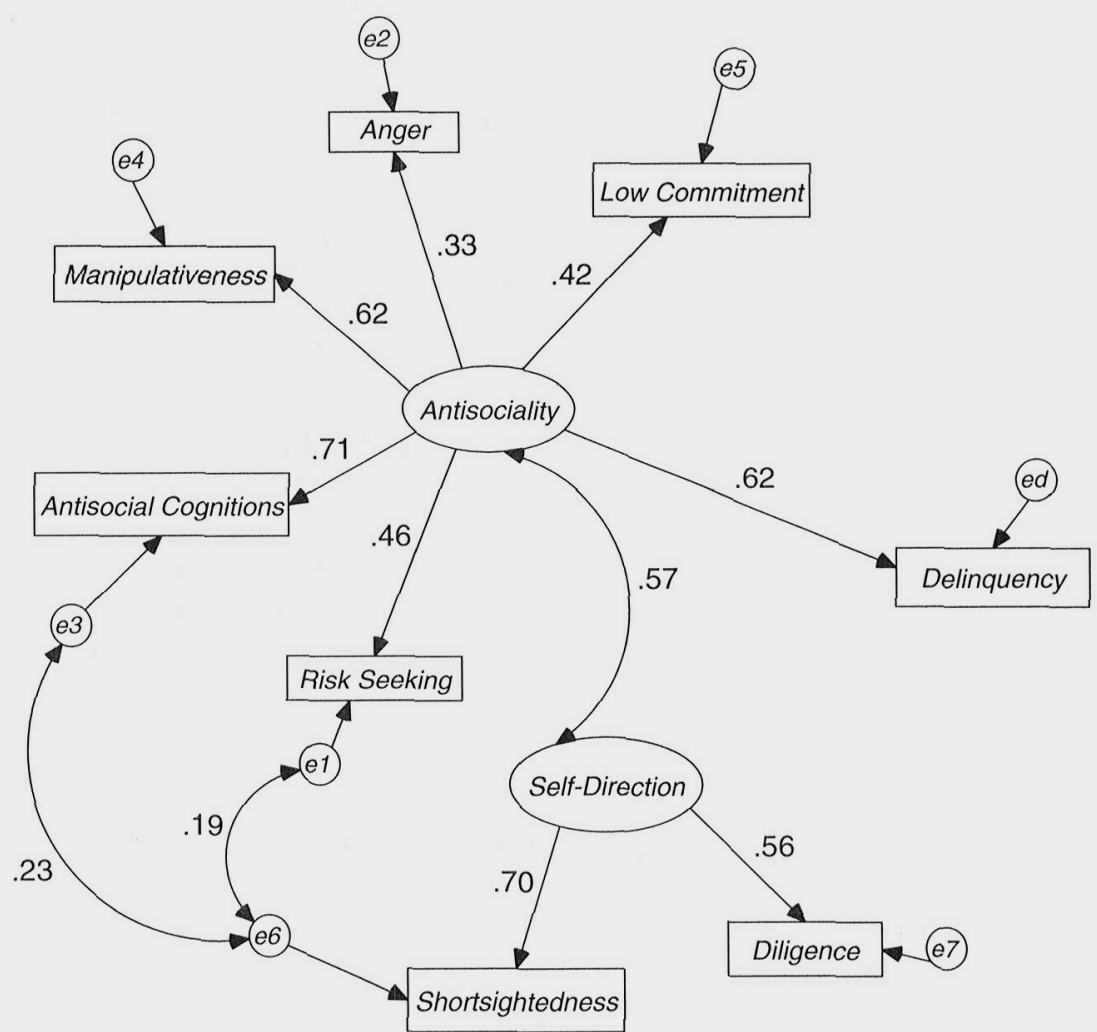

Note: Standardized coefficients for the full sample. $\chi^{2}=29.983,17 d f, p=.026$, $\mathrm{NFI}=.929, \mathrm{CFI}=.967, \mathrm{RMSEA}=.050, r^{2}$ for delinquency $=.39$.

Delinquency. Among females, the model achieved a good fit by the GFI, the AGFI, and the CFI and a reasonable fit by the RMSEA ( $\chi^{2}$ $=29.033, d f=18, p=.048, \mathrm{GFI}=.960, \mathrm{AGFI}=.921, \mathrm{NFI}=.866$, CFI $=.941$, RMSEA $=.063$ ) and explained $26 \%$ of the variance in offending. Among males, the model fit by all the criteria $\left(\chi^{2}=14.597, d f=\right.$ $18, p=.689, \mathrm{GFI}=.976, \mathrm{AGFI}=.952, \mathrm{NFI}=.920, \mathrm{CFI}=1.000$, RMSEA $=.000)$ and explained $38 \%$ of the variance in offending. Also similar to the results for the full sample, the higher-order model failed to improve fit statistics sufficiently to justify decreased parsimony. It explained $31 \%$ of the variance in offending among females and $48 \%$ among males.

\section{DISCUSSION}

This study appears to have been the first attempt to integrate two influential correlates of crime from different research traditions, self-control and psychopathy, to improve the prediction of offending. It also appears to have been the first to examine a new 
construct, Self-Direction, comprised of elements of self-control and psychopathy, that appears to be significantly related to offending. ${ }^{18}$ This research is important because it begins to combine the theoretical and empirical strengths of two separate research traditions and because it encourages a fresh look at the etiology of offending. Preventing crime may require attention not only to the causes of antisocial behavior, but to the causes of self-directed behavior as well.

The structural equation models that produced the best fit suggest that Antisociality, the degree to which one's activities are antisocial or prosocial, should be considered a separate construct from Self-Direction, the degree to which one is able and willing to work in one's own long-term self-interest. Alternative models, proposing a unitary self-control or psychopathy construct, or constructs representing primary and secondary psychopathy, fit these data poorly and were unequivocally rejected. No model proposing separate selfcontrol and psychopathy factors was tested because, given the considerable overlap between the two constructs, it would have had no meaning.

The results also suggest that the effects of Self-Direction on delinquency are indirect, working through Antisociality, implying a

18 Depending on how one reads Gottfredson and Hirschi (1990), the present results could be taken as a challenge to self-control theory. The inclusion of Diligence among the elements of self-control stems, in part, from the following quotation, on $p$. 89: "People lacking self-control also [omphasis added] tend to lack diligence, tenacity, or persistence in a course of action." If the presence of the word also were construed to mean that diligence is a correlate, not an element, of solf-control, tho ability of diligence to predict delinquency would somewhat contradict self-control theory, which considers low self-control to bo the sole important individual-level predictor of delinquency. It should also be noted that a lack of diligence is absent from the summary list of eloments of low self-control that appears on p. 90: "impulsive, insensitive, physical (as opposed to mental), risk-taking, shortsighted, and nonverbal." However, because a lack of diligence is consistent with the general definition of low self-control provided on p. 93, "an underlying tendency to pursue short-term, immediate pleasure," its exclusion would seem to result from an unnecessarily narrow reading of the theory. As I note later, it is not explicitly excluded, as are a tolerance for pain and sociability, from the construct. In general, I take the position that an understanding of the clements of self-control requires a reading of the entire general theory, not merely the list on p. 90. The good fit of the higher-order factor model suggests that it may be profitable to consider self-control an overarching construct comprised of at least two subordinate levels of traits. T'his position does not appoar to conflict significantly with Gottfredson and Hirschi's theory. In this model, Diligence loads on the same middle-range factor as Shortsightedness, a trait that appears in the summary list of self-control components (see also Grasmick et al., 1993).

At any rate, it is clear that Diligence is not considered to be wholly separate from self-control, a status granted to high pain tolerance and gregariousness, as illustrated by the following: "Crime requires the interaction of an offender with pcople or their property. It does not follow that people lacking sclf-control will tend to be gregarious or social. However, it does follow that, other things being equal, gregarious or social people are more likely to be involved in criminal acts" (p. 90). It is interesting to note that in regression models not reported in this article, the scale called Impulsive Sociability did not predict delinquency after other factors were controlled. However, this scale was probably not a strong-enough reprosentation of sociability and gregariousness to permit a convincing test of this aspect of the general theory. 
possible developmental process. Antisocial individuals, who tend to focus on immediate gratification without regard to future consequences (Gottfredson \& Hirschi, 1990), may be those for whom the alternative - the ability to persist at a task in the absence of immediate reward (Diligence)-never developed, possibly because of their belief that the future is uncertain and not worth working for (see Hill, Ross, \& Low, 1997). A test of this developmental model would, of course, require a longitudinal design.

Consistent with both self-control and psychopathy research, Antisociality and Self-Direction may themselves be manifestations of a higher-order construct. This study provided limited support for this hypothesis. Models with the higher-order construct fit the data well and explained more variance in offending than did models without this construct, but they did not exhibit large-enough improvements in model fit statistics to justify their additional complexity (see Widaman, 1985).

Along with integrating self-control and psychopathy, the second aim of the study was to explain variance in offending, and it did so substantially better, whether using regression or structural equation models, than have most studies that were based on selfcontrol. Pratt and Cullen's (2000) meta-analysis found that self-control explained only $6.9 \%$ of the variance in offending and other forms of deviance when measured attitudinally $(N=82)$, 7.7\% when measured behaviorally $(N=12)$, and $5.7 \%$ when predicting offending only $(N=62)$. In contrast, the explained variance in this study ranged from $36 \%$ to $53 \%$, depending on the subsample and method. In magnitude, it was comparable to the $30 \%$ found by Levenson et al. (1995), who measured self-reported psychopathy together with seven other traits plus GPA among a similar sample of university students, and the $42 \%$ found by Costello and Vowell (1999), who modeled social bonds as a latent variable among a sample of secondary school students. Taken together, these results support the findings of this study that low self-control, as currently conceived and measured, is not the last word in predicting delinquency from intrapersonal variables. ${ }^{19}$

What do the results of this study say about how psychopathy and low self-control can be reconciled? At least two difficulties must

19 This study did not measure opportunity for crime and therefore did not test the full general theory (Gottfredson \& Hirschi, 1990). It also did not use the Grasmick scale, so there is no way of knowing how much variance that scale would have accounted for in the present sample. Future research should include the entire Grasmick scale, along with the measures reported here. However, it should be noted that in the studies that formed the foundation for the meta-analysis described earlier, the Grasmick scale produced comparable results to other measures of self-control, explaining much less variance in offending than tie scales used in this study, as well as the measures used by Levenson et al. (1995) and Costello and Vowell (1999). 
be dealt with initially. The first lies in measurement. Proponents of both research traditions (e.g., Hare, 1996; Hirschi \& Gottfredson, 1993) have discouraged the use of self-report measures of their constructs, although researchers have developed self-report measures of each that have garnered some support among researchers (e.g., Grasmick et al., 1993; Levenson et al., 1995; Lilienfeld \& Andrews, 1996). But as an anonymous reviewer pointed out, given the assessment methods preferred by their proponents-interview and file review for psychopathy, behavioral correlates for self-control-it may be impossible to reconcile the two constructs except through a third method, such as self-report.

The second difficulty lies in the multiplicity of traits that are thought to make up the two constructs and the extent of their common content. Although they have similar roots, psychopathy and self-control have been the subjects of separate research traditions since the inception of self-control theory and, apparently as a result, are thought to comprise about 26 different intrapersonal traits and characteristic interpersonal styles, as well as (in the case of psychopathy) several different behaviors (see Table 1). At the least, this profligacy cries out for data reduction. Theoretically, many of these elements overlap; in the course of this study, much data reduction was performed at the item-selection level when items were chosen to represent what appeared to be homologous characteristics across the two constructs. Further data reduction occurred through exploratory factor analyses that produced 11 scales that appear to represent much of the intrapersonal and interpersonal content of both low self-control and psychopathy, in addition to one scale that did not fit within either construct. Overall, the results support Gottfredson and Hirschi's (1990) claim: Certain traits and tendencies that individually increase the probability of crime tend to occur together in the same individuals, producing a unitary syndrome that looks much like the "criminality" they decry. Furthermore, there does not seem to be any reason to assume that the relevant traits that were not well measured in this study, with the exception primarily of impulsivity, as distinguished from risk seeking, and low empathy.

But if self-control can accommodate these traits, what is the role of psychopathy? The practical answer, from a criminological viewpoint, is that the construct of psychopathy contains traits and tendencies that help to flesh out the portrait of the offender painted by self-control theory. This study married the hedonistic heedlessness of low self-control to the callous solipsism of psychopathy, and the couple, at least according to the confirmatory structural equation models reported here, resemble each other a great deal. This 
combination predicts delinquency better than prior research that used only self-control, an important result for criminology.

What remains unaddressed by this research is whether psychopathy represents an important, qualitatively unique, subgroup of offenders, or whether it merely describes individuals who have, by chance, a substantial number of traits associated with antisocial behavior. With at least one notable exception, the Darwinian theory of Mealey (1995), most psychopathy research has focused on description, whether of traits (e.g., Hare, 1993) or physiology (e.g., Forth \& Hare, 1989; Lynam, 1996; Patrick, 1994), rather than etiology. Future research comparing the etiology of psychopathy and low self-control may help to determine whether, from a criminological (rather than a clinical) viewpoint, psychopathy has value as a discrete construct (Harris, Rice, \& Quinsey, 1994). It may be important to know, for example, whether efforts to prevent criminality should differ from efforts to prevent psychopathy.

Gender differences. The models that fit best for the men and women examined separately were virtually identical to those that fit best for the full sample, differing only in their intercorrelated error terms. However, the models fit less well and explained less variance among women than among men and the full sample. They may have done so, in part, because the variance in offending was smaller in magnitude among the women or because of subtle differences in the causes of crime between the men and the women. Neither selfcontrol nor psychopathy theory predicts major differences between the sexes (but see Harpending \& Draper, 1986; McHoskey, 2001).

One interesting gender difference involved Risk Seeking. This scale was irrelevant among the males for predicting delinquency ( $p$ $=.130$ ) but strongly predicted it among the females $(p<.0005)$. It is possible that this scale taps into an actual difference in the availability of socially acceptable outlets for risk-seeking men and women (see Lykken, 1995). It is also possible, as one anonymous reviewer suggested, that the behaviors represented by the specific items in the study-skydiving, testing oneself by taking risks-are more socially acceptable for men than for women. Thus, women who endorsed these items would be more deviant than men who endorsed them. Future studies should seek to collect a set of gender-neutral indicators of risk seeking.

\section{Study Limitations, Recommendations}

Although this study attempted to integrate psychopathy and low self-control, it is not claimed that any differences between them are solely artifacts of disciplinary boundaries (see Campbell, 1969). 
Integrative efforts can illuminate not only what research programs have in common, but where they are truly different. For example, this study did not address whether psychopathy, especially in its primary form, is simply an extreme version of low self-control or is a discrete syndrome that may share some of the characteristics of low self-control but is a psychological entity in and of itself (Harris, Rice, \& Quinsey, 1994; see also Mealey, 1995). Future studies should therefore use orthodox measures of psychopathy, as well as other measures of antisocial characteristics and Self-Direction, on samples that include a substantial proportion of psychopaths.

Related to this limitation is the overarching issue of construct validity. As an anonymous reviewer noted, the study did not use previously validated measures of psychopathy and self-control, although it did use many individual items that had previously been used to measure self-control. Although it would appear simple, at first glance, to resolve this difficulty by using validated measures, there may be more to this problem than meets the eye. First, no single self-report measure of psychopathy has been widely accepted by the field. Second, although some measures have been validated against the PCL-R (e.g., Lilienfeld \& Andrews, 1996), it is not clear that the PCL-R represents the ideal prototype for psychopathy (Lilienfeld, 1994; Raine, 1985); for example, its emphasis on criminal and delinquent behavior appears to be at odds with Cleckley's (1941) formulation. And third, the most widely used self-report measure of self-control, the Grasmick scale, suffers from its own limitations (see $\mathrm{fn} 9$ ), not the least of which is its relative lack of predictive validity, as evinced by its characteristically modest ability to account for variance in offending (Pratt \& Cullen, 2000). Future research should pay close attention to the issue of construct validity; perhaps the current study, by paying close attention to the factor structure of a collection of intrapersonal predictors of delinquency, can assist in this endeavor.

These data suffered from a few limitations even to test the stated goals of this study using a unique set of self-report items. First, only self-report data were used. Future studies should measure personality variables and offending from other vantage points as well, especially in light of the criticisms of self-report data leveled by both psychopathy researchers (Hare, 1985; but see Levenson, et al., 1995; Lilienfeld \& Andrews, 1996; Lynam et al., 1999) and self-control researchers (Hirschi \& Gottfredson, 1993; but see Grasmick et al., 1993). 
Second, these data were obtained from college students, hardly a representative sample. Thus, the generalizability of the Antisociality/Self-Direction model remains to be established. Criminological research from various perspectives, including self-control, social control, and strain theories, however, make it clear that the building blocks of Self-Direction-Diligence and (low) Shortsightedness-are themselves valid predictors of offending.

Third, these data were cross-sectional in nature. SEM suggested a path from Self-Direction through Antisociality to offending, but examining whether this is a valid developmental model will require longitudinal research. Such research could also examine the causes of Antisociality and Self-Direction themselves, which were exogenous variables in this study. Longitudinal studies of the causes and development of Antisociality and Self-Direction, as well as the relationship between them, could have important implications for interventions to prevent the development of delinquency.

Fourth, reports of offending were retrospective. Under self-control theory, intrapersonal characteristics relevant to offending are thought to remain relatively stable within cohorts, so present traits should explain past offending (Arneklev et al., 1998). However, the possibility for personality change exists. Substantial change, of course, may attenuate, rather than augment, the variance explained by the model.

Fifth, the measures themselves could use further development. Since many of the alphas were fairly low and some of the constructs were underrepresented, an iterative process to refine a set of scales corresponding to each of the elements uncovered by the first-order factor analysis, such as that used by Lilienfeld (1991) and Lilienfeld and Andrews (1996), should follow the single round reported here. Items from other sources, such as Zuckerman's (1994) Sensationseeking scale, could help to unpack the Impulsive Sociability scale; to measure Anger, Risk-Seeking, and Guiltlessness more fully; and to gain a better understanding of the nature of Diligence. Furthermore, the factors derived here contained unequal numbers of manifest indicators. Future studies should attempt to achieve more balance. It is not expected, however, that the elements that require better measures-impulsivity, the lack of guilt or remorse, and risk seeking-would significantly alter the factor structure supported here if they were measured better. This assertion could be tested in future studies by using confirmatory SEM to compare models with improved measures to models incorporating the measures derived in this study. 
Finally, future studies should add measures of environmental variables to intrapersonal variables to test the entire general theory of crime (Gottfredson \& Hirschi, 1990) - that is, by including measures of opportunity for offending (e.g., Costello \& Vowell 1999; LaGrange \& Silverman, 1999). In view of the results of this study, it may be wise to add measures of opportunities for prosocial and self-directed activities as well (Wiebe, in press). The idea that such opportunities are important is nothing new; many prevention and rehabilitation programs include environmental supports, such as job placement and supervision, to accompany the psychological changes achieved by their clients (see, e.g., Milan, Chin, \& Nguyen, 1999). But the model of the intrapersonal correlates of crime proposed here, combined with an expanded notion of opportunity, could, if validated by future studies, provide a strong foundation, both theoretical and empirical, for the development of integrated interventions, as well as a template for their evaluation.

\section{REFERENCES}

Arbuckle, J. L. (1999). AMOS [Computer software]. Chicago: SmallWaters.

Arbuckle, J. L., \& Wothke, W. (1999). Amos 4.0 user's guide. Chicago: SmallWaters.

Arneklev, B. J., Cochran, J. K., \& Gainey, R. R. (1998). Testing Gottfredson and Hirschi's "low self-control" stability hypothesis: An exploratory study. American Journal of Criminal Justice, 23, 107-127.

Arneklev, B. J., Grasmick, H. G., \& Bursik, R. J. Jr. (1999). Evaluating the dimensionality and invariance of "Iow self-control". Journal of Quantitative Criminology, 15, 307-331.

Bandura, A. (1977). Social learning theory. Englewood Cliffs, NJ: Prentice-Hall.

Bandura, A. (1986). Social foundations of thought and action. Englewood Cliffs, NJ: Prentice-Hall.

Basilevsky, A. (1994). Statistical factor analysis and related methods. New York: John Wiley \& Sons.

Baumeister, R. F., \& Exline, J. J. (2000). Self-control, morality, and human strength. Journal of Social and Clinical Psychology, 19, 29-42.

Belmore, M. F., \& Quinsey, V. L. (1994). Correlates of psychopathy in a noninstitutional sample. Journal of Interpersonal Violence, 9, 339-349.

Bentler, P. (1990). Comparative fit indexes in structural models. Psychological Bulletin, 107, 238-246.

Bentler, P. M., \& Bonnett, D. G. (1980). Significance tests and goodness of fit in the analysis of covariance structures. Psychological Bulletin, 88, 588-606.

Blackburn, R. (1988). On moral judgements and personality disorders: The myth of psychopathic personality revisited. British Journal of Psychiatry, 153, 505-512.

Blackburn, R., \& Fawcett, D. (1999). The Antisocial Personality Questionnaire: An inventory for assessing personality deviation in offender populations. European Journal of Psychological Assessment, 15, 14-24.

Block, J., \& Gjerde, P. F. (1986). Distinguishing between antisocial behavior and undercontrol. In D. Olweus, J. Block, \& M. Radke-Yarrow (Eds.), Development of antisocial and prosocial behavior: Research, theories, and issues (pp. 177-206). Orlando, FL: Academic Press.

Bollen, K. A., \& Long, J. S. (1993). Introduction. In K. A. Bollen \& J. S. Long (Eds.), Testing structural equation models (pp. 1-9). Newbury Park, CA: Sage.

Brannigan, A. (1997). Self control, social control and evolutionary psychology: Toward an integrated perspective on crime. Canadian Journal of Criminology, 39, 403-431. 
Brownfield, D., \& Sorenson, A. M. (1993). Self-control and juvenile delinquency: Theoretical issues and an empirical assessment of selected elements of a general theory of crime. Deviant Behavior, 14, 243-264.

Buss, A. H. (1961). The psychology of aggression. New York: John Wiley \& Sons.

Byrne, B. M. (1994). Structural equation modeling with EQS and EQS/Windows. Thousand Oaks, CA: Sage.

Campbell, D. T. (1969). Ethnocentrism of disciplines and the fish-scale model of omniscience. In M. Sherif \& C. W. Sherif (Eds.), Interdisciplinary relationships in the social sciences (pp. 328-348). Chicago: Aldine.

Cleckley, H. (1941). The mask of sanity. St. Louis: C. V. Mosby.

Cleckley, H. (1964). The mask of sanity (4th ed.). St. Louis: C. V. Mosby.

Cloninger, C. R., Svrakic, D. M., \& Przbeck, T. R. (1993). A psychobiological model of temperament and character. Archives of General Psychiatry, 50, 973-990.

Cooke, D. J., \& Michie, C. (2001). Refining the construct of psychopathy: Towards a hierarchical model. Psychological Assessment, 13, 171-188.

Costello, B. J., \& Vowell, P. R. (1999). Testing control theory and differential association: A reanalysis of the Richmond Youth Project data. Criminology, 37, 815842.

Crombach, L. J. (1951). Coefficient alpha and the internal structure of tests. Psychometrika, 16, 297-334.

Cunningham, M. D., \& Reidy, T. J. (1998). Antisocial personality disorder and psychopathy: Diagnostic dilemmas in classifying patterns of antisocial behavior in sentencing evaluations. Behavioral Sciences and the Law, 16, 333-351.

Diamantopoulos, A., \& Siguaw, J. A. (2000). Introducing LISREL. London: Sage.

Figueredo, A. J., Cox, R. L., \& Rhine, R. J. (1995). A generalizability analysis of subjective personality assessments in the stumptail macaque and the Zebra finch. Multivariate Behavioral Research, 30, 167-197.

Forth, A. E., \& Hare, R. D. (1989). The contingent negative variation in psychopaths. Psychophysiology, 26, 676-682.

Frank, R. H. (1988). Passions within reason: The strategic role of the emotions. New York: W. W. Norton.

Gerbing, D. W., \& Anderson, J. C. (1993). Monte Carlo evaluations of goodness-of-fit indices for structural equations models. In K. A. Bollen \& J. S. Long (Eds.), Testing structural equation models (pp. 40-65). Newbury Park, CA: Sage.

Gibbs, J. J., \& Giever, D. (1995). Self-control and its manifestations among university students: An empirical test of Gottfredson and Hirschi's general theory. Justice Quarterly, 12, 231-255.

Glueck, S., \& Glueck, E, (1950). Unraveling juvenile delinquency. New York: Commonwealth Fund.

Goldberg, L. R. (1990). An alternative "description of personality": The Big Five factor structure. Journal of Personality and Social Psychology, 59, 1216-1229.

Gottfredson, M. R., \& Hirschi, T. (1990). A general theory of crime. Stanford, CA: Stanford University Press.

Gough, H. (1948). A sociological theory of psychopathy. American Journal of Sociology, 53, 359-366.

Grasmick, H. G., Tittle, C. R., Bursik, R. J., \& Arneklev, B. J. (1993). Testing the core empirical implications of Gottfredson and Hirschi's general theory of crime. Journal of Research in Crime and Delinquency, 30, 5-29.

Hare, R. D. (1980). A research scale for the assessment of psychopathy in criminal populations. Personality and Individual Differences, 1, 111-119.

Hare, R. D. (1985). Comparison of procedures for the assessment of psychopathy. Journal of Consulting and Clinical Psychology, 53, 7-16.

Hare, R. D. (1993). Without conscience: The disturbing world of the psychopaths among us. New York: Pocket Books.

Hare, R. D. (1996). Psychopathy: A construct whose time has come. Criminal Justice and Behavior, 23, 25-54.

Hare, R. D., Harpur, T. J., Hakstian, A. R., Forth, A. E., Hart, S. D., \& Newman, J. P. (1990). The Revised Psychopathy Checklist: Reliability and factor structure. Psychological Assessment, 2, 338-341.

Hare, R. D., \& Hart, S. D. (1993). Psychopathy, mental disorder, and crime. In S. Hodgins (Ed.), Mental disorder and crime (pp. 104-115). Newbury Park, CA: Sage. 
Harpending, H., \& Draper, P. (1986). Antisocial behavior and the other side of cultural evolution. In T. E. Moffitt, \& S. A. Mednick (Eds.), Biological contributions to crime causation (pp. 293-307). Boston: Martinus Nijhoff.

Harpur, T. J., Hare, R. D., \& Hakstian, A. R. (1989). Two-factor conceptualization of psychopathy: Construct validity and assessment implications. Psychological Assessment, 1, 6-17.

Harpur, T. J., Hart, S. D., \& Hare, R. D. (1994). Personality of the psychopath. In P. T. Costa, Jr., \& T. A. Widiger (Eds.), Personality disorders and the five-factor model of personality (pp. 149-173). Washington, DC: American Psychological Association.

Harris, G. T., Rice, M. E., \& Cormier, C. A. (1994). Psychopaths: Is a therapeutic community therapeutic? Therapeutic Communities, 15, 283-299.

Harris, G. T., Rice, M. E., \& Quinsey, V. L. (1994). Psychopathy as a taxon: Evidence that psychopaths are a discrete class. Joumal of Consulting and Clinical Psychology, 62, 387-397.

Hayduk, L. A. (1996). LISREL: Issues, debates, and strategies. Baltimore, MD: Johns Hopkins University Press.

Hayduk, L.A., \& Glaser, D. A. (2000). Jiving the four-step, waltzing around factor analysis, and other serious fun. Structural Equation Modeling, 7, 1-35.

Heaven, P. C. L. (1996). Personality and self-reported delinquency: Analysis of the "Big Five" personality dimensions. Personality and Individual Differences, 20 , 47-54.

Hill, E. M., Ross, L. T., \& Low, B. S. (1997). The role of future unpredictability in human risk-taking. Human Nature, 8, 287-325.

Hirschi, T. (1969). Causes of delinquency. Berkeley: University of California Press.

Hirschi, T. (1994). Family. In T. Hirschi \& M. R. Gottfredson (Eds.), The generality of deviance (pp. 47-69). Boston: Transaction Press.

Hirschi, 'T., \& Gottfredson, M. (1993). Commentary: Testing the general theory of crime. Journal of Research in Crime and Delinquency, 30, 47-54.

Hirschi, T., \& Gottfredson, M. R. (1995). Control theory and the life-course perspective. Studies on Crime and Crime Prevention, 4, 131-142.

Hirschi, T., \& Gottfredson, M. (2001). Self-control theory. In R. Paternoster \& R. Bachman (Eds.), Explaining criminals and crime (pp. 81-96). Los Angeles: Roxbury.

Hirschi, T., \& Gottfredson, M. R. (1995). Control theory and the life-course perspective. Studies on Crime and Crime Prevention, 4, 131-142.

Jöreskog, K. G. (1993). Testing structural equation models. In K. A. Bollen \& J. S. Long (Eds.), Testing structural equation models (pp. 294-316). Newbury Park, CA: Sage.

Kim, J.-O., \& Mueller, C. W. (1978). Factor analysis: Statistical methods and practical issues. Sage University Paper series on Quantitative Applications in the Social Sciences No. 07-014. Beverly Hills, CA: Sage.

Krueger, R. F., Caspi, A., Moffitt, T. E., White, J., \& Stouthamer-Loeber, M. (1996). Delay of gratification, psychopathology, and personality: Is low self-control specific to externalizing problems? Journal of Personality, 64, 107-129.

LaGrange, T. C., \& Silverman, R. A. (1999). Low self-control and opportunity: Testing the general theory of crime as an explanation for gender differences in delinquency. Criminology, 37, 41-72.

Levenson, M. R. (1992). Rethinking psychopathy. Theory \& Psychology, 2, 51-71.

Levenson, M. R., Kiehl, K. A., \& Fitzpatrick, C. M. (1995). Assessing psychopathic attributes in a noninstitutionalized population. Journal of Personality and Social Psychology, 68, 151-158.

Lilienfeld, S. O. (1991). Development and preliminary validation of a self-report measure of psychopathy (Doctoral dissertation, University of Minnesota, 1990). Dissertation Abstracts International, 51 (8B), 4057.

Lilienfeld, S. O. (1994). Conceptual problems in the assessment of psychopathy. Clinical Psychology Review, 14, 17-38.

Lilienfeld, S. O., \& Andrews, B. P. (1996). Development and preliminary validation of a self-report measure of psychopathic personality traits in noncriminal populations. Journal of Personality Assessment, 66, 488-524.

Long, J. S. (1983). Confirmatory factor analysis (Sage University Paper Series on Quantitative Application in the Social Sciences, 07-033). Beverly Hills, CA: Sage. 
Longshore, D., Stein, J. A., \& Turner, S. (1998). Reliability and validity of a selfcontrol measure: A rejoinder. Criminology, 36, 175-182.

Longshore, D., Turner, S., \& Stein, J. A. (1996). Self-control in a criminal sample: An examination of construct validity. Criminology, 34, 209-228.

Ludwig, K. B., \& Pittman, J. F. (1999). Adolescent prosocial values and self-efficacy in relation to delinquency, risky sexual behavior, and drug use. Youth \& Society, $30,461-482$

Lykken, D. T. (1957). A study of anxiety in the sociopathic personality. Journal of Abnormal and Social Psychology, 55, 6-10.

Lykken, D. T. (1995). The antisocial personalities. Hillsdale, NJ: Lawrence Erlbaum.

Lynam, D. R. (1996). Early identification of chronic offenders: Who is the fledgling psychopath? Psychological Bulletin, 120, 209-234.

Lynam, D. R., Whiteside, S., \& Jones, S. (1999). Self-reported psychopathy: A validation study. Journal of Personality Assessment, 73, 110-132.

Maruna, S. (2001). Making good: How ex-convicts reform and rebuild their lives. Washington, DC: American Psychological Association.

McCrae, R. R., \& John, O. P. (1992). An introduction to the five-factor model and its applications. Journal of Personality, 60, 175-215.

McHoskey, J. W. (2001). Machiavellianism and sexuality: On the moderating role of biological sex. Personality and Individual Differences, 31, 779-789.

Mealey, L. (1995). The sociobiology of sociopathy: An integrated evolutionary model. Behavioral and Brain Sciences, 18, 523-599.

Meehl, P. E. (1992). Factors and taxa, traits and types, differences of degree and differences in kind. Journal of Personality, 60, 117-174.

Milan, M. A., Chin, C. E., \& Nguyen, Q. X (1999). Practicing psychology in correctional settings: Assessment, treatment, and substance abuse programs. In A. H. Hess \& I. B. Weiner (Eds.), The handbook of forensic psychology (pp. 580-602). New York: John Wiley \& Sons.

Miller, J. D., \& Lynam, D. R. (2001). Structural models of personality and their relation to antisocial behavior: A meta-analytic review. Criminology, 39, 765-798.

Miller, J. D., Lynam, D. R., Widiger, T. A., \& Leukefeld, C. (2001). Personality disorders as extreme variants of comon personality dimensions: Can the five-factor model adequately represent psychopathy? Journal of Personality, 69, 253-276.

Muraven, M., \& Baumeister, R. F. (2000). Self-regulation and depletion of limited resources: Does self-control resemble a muscle? Psychological Bulletin, 126, 247259.

Nesse, R. M. (1990). Evolutionary explanations of emotions. Human Nature, 1, 261289.

Norusis, M. J. (1990). SPSS Base system user's guide. Chicago: SPSS.

Patrick, C. J. (1994). Emotion and psychopathy: Startling new insights. Psychophysiology, 31, 319-330.

Peterson, D. R., Quay, H. C., \& Cameron, G. R. (1959). Personality and background factors in juvenile delinquency as inferred from questionnaire responses. Journal of Consulting Psychology, 23, 295-299.

Piquero, A. R., MacIntosh, R., \& Hickman, M. (2000). Does self-control affect survey response? Applying exploratory, confirmatory and item response theory analysis to Grasmick et al.'s self-control scale. Criminology, 38, 897-929.

Piquero, A. R., \& Rosay, A. B. (1998). The reliability and validity of Grasmick et al.'s self-control scale: A comment on Longshore et al. Criminology, 36, 157-173.

Polakowski, M. (1994). Linking self- and social control with deviance: Illuminating the structure underlying a general theory of crime and its relation to deviant activity. Journal of Quantitative Criminology, 10, 41-78.

Pratt, T., \& Cullen, F. T. (2000). The empirical status of Gottfredson and Hirschi's general theory of crime: A meta-analysis. Criminology, 38, 931-964.

Quinsey, V. L. (1995). The prediction and explanation of criminal violence. International Journal of Law and Psychiatry, 18, 117-127.

Quinsey, V. L., Book, A., \& Lalumiere, M. L. (2001). A factor analysis of traits related to individual differences in antisocial behavior. Criminal Justice and Behavior, $28,522-536$.

Raine, A. (1985). A psychometric assessment of Hare's checklist for psychopathy on an English prison population. British Journal of Clinical Psychology, 24, 247258.

Reise, S. P., \& Oliver, C. J. (1994). Development of a California Q-Set indicator of primary psychopathy. Journal of Personality Assessment, 62, 130-144. 
Rosay, A. B. (1999). Narrowing the causes of criminal and analogous behaviors from self-control to risk-seeking. Paper presented at the annual meeting of the American Society of Criminology, Toronto.

Sampson, R. J., \& Laub, J. H. (1993). Crime in the making: Pathways and turning points through life. Cambridge, MA: Harvard University Press.

Saucier, G., \& Goldberg, L. R. (1996). The language of personality: Lexical perspectives on the five-factor model. In J. S. Wiggins (Ed.), The five-factor model of personality: Theoretical perspectives (pp. 21-50). New York: Guilford Press.

Sykes, G. M., \& Matza, D. (1957). Techniques of neutralization: A theory of delinquency. American Sociological Review, 22, 664-670.

Tabachnick, B. G., \& Fidell, L. S. (1996). Using multivariate statistics (3rd edition). New York: HarperCollins.

Widaman, K. F. (1985). Hierarchically nested covariance structural models for multitrait-multimethod data. Applied Psychological Measurement, 9, 1-26.

Widaman, K. F. (1993). Common factor analysis versus principal component analysis: Differential bias in representing model parameters? Multivariate Behavioral Research, 28, 263-311.

Widom, C. S. (1977). A methodology for studying noninstitutionalized psychopaths. Journal of Consulting and Clinical Psychology, 45, 674-683.

Wiebe, R. P. (in press). Expanding the model of human nature underlying the general theory of crime: Implications for the constructs of self-control and opportunity. Australian and New Zealand Journal of Criminology.

Wilson, J. Q. (1993). The moral sense. New York: Free Press.

Wulfert, E., Block, J. A., Santa Ana, E., Rodriguez, M. L., \& Colsman, M. (2002). Delay of gratification: Impulsive choices and problem behaviors in early and late adolescence. Journal of Personality, 70, 533-552.

Zuckerman, M. L. (1994). Impulsive unsocialized sensation seeking: The biological foundations of a basic dimension of personality. In J. E. Bates \& T. D. Wachs (Eds.), Temperament: Individual differences at the interface of biology and behavior (pp. 219-255). Washington, DC: American Psychological Association. 


\section{Appendix A. Factors, Items, and Loadings}

\begin{tabular}{ll}
\hline Item & Factor Loading
\end{tabular}

Anger

1. Some people think I am hot-headed. $\quad 1.07^{\mathrm{a}}$

2. I lose my temper really easily. $\quad .56$

Antisocial Cognitions

3. It's OK to steal something that's covered by insurance. $\quad .71$

4. It's OK to get around the law if you can get away with it. $\quad .60$

5. Only fools tell the truth all the time. $\quad .60$

6. It's OK to take something from big businesses because they won't miss it anyway (shared with Sullen).

7. To get ahead, you have to do some things that are not right.

8. Rules were made to be broken.

9. I see no need for hard work (shared with Shortsightedness).

10. Cheating and lying are always wrong, whatever the situation.

12. When it comes right down to it, everyone's a criminal. Attachment

13. I share my thoughts and feelings with my mother.

14. My mother seems to understand me.

15. I would like to be the kind of person my mother is.

Diligence

16. I try hard in school.

17. Whatever I do, I try hard.

18. I like school (shared with Sullen).

19. I don't devote much thought and effort to preparing for the future (shared with Shortsightedness)

20. I try to save as much money as I can. ${ }^{\mathrm{b}}$

Guiltless

21. I have never done anything I am ashamed of.

22. I don't waste time worrying about the bad things I have done.

23. On the whole, I am satisfied with myself (shared with Shortsightedness).

24. I care about what other people think of me (shared with Impulsive Sociability)

25. There are some things my conscience won't let me do.

26. It hurts me to see people suffer. ${ }^{\text {c }}$

Impulsive Sociability

27. My social life is extremely important to me.

28. I seldom pass up the opportunity to have a good time.

24. I care about what other people think of me (shared with Guiltless).

29. I'd rather have great looks than exceptional intelligence.

30. I often do whatever brings me pleasure in the here and now, even at the cost of some distant goal (shared with Shortsightedness).

Manipulativeness

31. When I get caught in a lie, I just tell another one.

32. I try to get the things I want even when I know it's causing problems for other people.

33. My lies work best when they contain some truth. truth. 
[Appendix A, cont.]

Low Commitment

36. "One night stands" are not for me.

37. There is something especially exciting about casual sex.

38. I have had sex with more than one partner in the same week.

39. I am naturally monogamous.

Respect

40. The police try to give everyone an even break. .90

41. I have lots of respect for the police.

42. People who break the law are almost always caught and punished.

Risk Seeking

43. Sometimes I take a risk just for the fun of it.

44. I like to test myself by doing risky things.

45. Skydiving would be fun.

46. A person should live for today and let tomorrow take care of itself (shared with Shortsightedness).

Shortsightedness

47. There is no sense looking ahead because no one knows what the future will be like.

48. I do not have much to be proud of.

46. A person should live for today and let tomorrow take care of itself (shared with Risk Seeking).

49. What is going to happen to me will happen, no matter what I do.

9. I see no need for hard work (shared with Antisocial).

19. I don't devote much thought and effort to preparing for the future (shared with Diligence).

30. I often do whatever brings me pleasure in the here and now, even at the cost of some distant goal (shared with Social).

23. On the whole, I am satisfied with myself (shared with Guiltless).

Sullen

18. I like school (shared with Diligent).

50. There are some people I hate.

51. I am shy and reserved in social settings.

6. It's OK to take something from big businesses because they won't miss it anyway (shared with Antisocial).

35. I can carry a grudge for a long time (shared with Manipulativeness).

Discarded Items

52. Fools and suckers deserve what they get.

53. Hitchhiking is too dangerous for me.

54. I am really just an ordinary person.

55. I am usually pretty cautious.

56. I don't understand how some people can sit and read for hours.

57. I think young people should respect tradition more than they do nowadays.

58. I'd rather have 10 really good years and die young than be watching TV in a rocking chair when I'm 70.

59. If I don't do everything by the book, I feel guilty.

60. If people are victims of crime, it's nobody's fault but their own.

61. It's easy to trick people out of their money. 
[Appendix A, cont.]

62. Most people can be trusted

63. Most things people call delinquency don't really hurt anyone.

64. No one would think of me as a nerd.

65. Telling a good lie is a real challenge.

${ }^{a}$ Oblique solution permits loadings greater than 1.0.

${ }^{\mathrm{b}}$ This Item, which explained less variance than any other item overall, also had .311 loading on Sullen, but this loading was not stable across solutions and was excluded from that factor while retained on Diligent. When added to Sullen, the item reduced the coefficient alpha from .50 to .37 .

c This Item increased the coefficient alpha from .46 to .50 and was retained despite low loading. 
Appendix B. Correlation Matrix for Structural Equation Models $(N=306)$

\begin{tabular}{|c|c|c|c|c|c|c|c|c|}
\hline & Angr & Anti & Dil & LowC & Mnip & Risk & Shrt & Dlnq \\
\hline Anger & & .0005 & .291 & .143 & .0005 & .067 & .002 & .002 \\
\hline Antisocial Cognitions & $.230^{* *}$ & & .0005 & .0005 & .0005 & .0005 & .0005 & .0005 \\
\hline Diligence & .061 & $.248 * *$ & & .010 & .014 & .244 & .0005 & .0005 \\
\hline Low Commitment & .084 & $.276 * *$ & $.147 *$ & & .0005 & .0005 & .029 & .0005 \\
\hline Manipulativeness & $.309^{* *}$ & $.447 * *$ & $.141 *$ & $.228 * *$ & & .0005 & .0005 & .0005 \\
\hline Risk Seeking & .105 & $.378 * *$ & .067 & .239 ** & $.267 * *$ & & .0005 & .0005 \\
\hline Shortsightedness & $.173^{* *}$ & $.412 * *$ &. $\mathbf{3 8 5} * *$ & $.125 *$ & $.235 * *$ & $.295^{* *}$ & & .0005 \\
\hline Delinquency & $.178^{* *}$ & $.417 * *$ & $.294 * *$ & $.323^{* *}$ & $.388 * *$ & $.256^{* *}$ & $.263^{* *}$ & \\
\hline
\end{tabular}

Note: Below the diagonal, bivariate correlations (bold); above the diagonal, probabilities (italics). .0005 means less than or equal to .0005 .

* Significant at $p<.05$; ** significant at $p<.005$. 